\title{
The impact of leadership hubs on the uptake of evidence-informed nursing practices and workplace policies for HIV care: a quasi-experimental study in Jamaica, Kenya, Uganda and South Africa
}

Nancy Edwards ${ }^{1 *}$ (D) Dan Kaseje ${ }^{2}$, Eulalia Kahwa ${ }^{3}$, Hester C. Klopper ${ }^{4}$, Judy Mill $^{5}$, June Webber ${ }^{6}$, Susan Roelofs ${ }^{1}$ and Jean Harrowing ${ }^{7}$

\begin{abstract}
Background: The enormous impact of HIV on communities and health services in Sub-Saharan Africa and the Caribbean has especially affected nurses, who comprise the largest proportion of the health workforce in low- and middle-income countries (LMICS). Strengthening action-based leadership for and by nurses is a means to improve the uptake of evidence-informed practices for HIV care.

Methods: A prospective quasi-experimental study in Jamaica, Kenya, Uganda and South Africa examined the impact of establishing multi-stakeholder leadership hubs on evidence-informed HIV care practices. Hub members were engaged through a participatory action research (PAR) approach. Three intervention districts were purposefully selected in each country, and three control districts were chosen in Jamaica, Kenya and Uganda. WHO level 3, 4 and 5 health care institutions and their employed nurses were randomly sampled. Self-administered, validated instruments measured clinical practices (reports of self and peers), quality assurance, work place policies and stigma at baseline and follow-up. Standardised average scores ranging from 0 to 1 were computed for clinical practices, quality assurance and work place policies. Stigma scores were summarised as 0 (no reports) versus 1 (one or more reports). Pre-post differences in outcomes between intervention and control groups were compared using the Mantel Haenszel chi-square for dichotomised stigma scores, and independent $t$ tests for other measures. For South Africa, which had no control group, pre-post differences were compared using a Pearson chi-square and independent $t$ test. Multivariate analysis was completed for Jamaica and Kenya. Hub members in all countries self-assessed changes in their capacity at follow-up; these were examined using a paired $t$ test.

(Continued on next page)
\end{abstract}

\footnotetext{
* Correspondence: nedwards@uottawa.ca

${ }^{1}$ School of Nursing, Faculty of Health Sciences, University of Ottawa, Ottawa,

Canada

Full list of author information is available at the end of the article
} 
(Continued from previous page)

Results: Response rates among health care institutions were 90.2 and $80.4 \%$ at baseline and follow-up, respectively. Results were mixed. There were small but statistically significant pre-post, intervention versus control district improvements in workplace policies and quality assurance in Jamaica, but these were primarily due to a decline in scores in the control group. There were modest improvements in clinical practices, workplace policies and quality assurance in South Africa (pre-post) (clinical practices of self-pre $0.67(95 \% \mathrm{Cl}, 0.62,0.72)$ versus post 0.78 (95\% Cl, 0.73-0.82), $p=0.002$; workplace policies-pre $0.82(95 \% \mathrm{Cl}, 0.70,0.85)$ versus post $0.87(95 \% \mathrm{Cl}, 0.84,0.90)$, $p=0.001$; quality assurance-pre $0.72(95 \% \mathrm{Cl}, 0.67,0.77)$ versus post $0.84(95 \% \mathrm{Cl}, 0.80,0.88)$ ). There were statistically significant improvements in scores for nurses stigmatising patients (Jamaica reports of not stigmatising — pre-post intervention 33.9 versus $62.4 \%$, pre-post control 54.7 versus $64.4 \%, p=0.002$-and Kenya pre-post intervention 35 versus $51.6 \%$, pre-post control 34.2 versus $47.8 \%, p=0.006$ ) and for nurses being stigmatised (Kenya reports of no stigmatisation-pre-post intervention 23 versus $37.3 \%$, pre-post control 15.4 versus $27 \%, p=0.004$ ). Multivariate results for Kenya and Jamaica were non-significant. Twelve hubs were established; 11 were active at follow-up. Hub members $(n=34)$ reported significant improvements in their capacity to address care gaps.

Conclusions: Leadership hubs, comprising nurses and other stakeholders committed to change and provided with capacity building can collectively identify issues and act on strategies that may improve practice and policy. Overall, hubs did not provide the necessary force to improve the uptake of evidence-informed HIV care in their districts. If hubs are to succeed, they must be integrated within district health authorities and become part of formal, legal organisations that can regularise and sustain them.

Keywords: Nurses, Leadership, Participatory action research, HIV, Low- and middle-income countries, Capacity building, Health system strengthening, Evidence-informed clinical practice, Workplace policies, Quality assurance, Stigma

\section{Background}

HIV has had an enormous impact on the health of communities and on models of service delivery [1-5] particularly in sub-Saharan Africa, and more recently in the Caribbean. While all health providers have had to deal with this epidemic, nurses and midwives ${ }^{1}$ who deliver direct client care and comprise the largest proportion of the health workforce in low- and middle- income countries (LMICs) have been especially affected. Severe nursing shortages and unrealistically low nurse-to-patient care ratios are entwined with the impact of stigmatisation, workplace safety and health service delivery in HIV prevalent settings [5-13]. These have all contributed to significant gaps in HIV care in LMICs [14-16].

Efforts to address these gaps have been targeted at different facets of the problem. Extensive professional development training and mentoring programmes for nurses have focused on clinical skills and scope of practice [17]. These have included strategies to reduce HIV stigma [12, 18], to improve patient counselling on adherence to anti-retroviral therapy (ART) [19], to enhance voluntary testing and counselling for HIV testing $[19,20]$ and to increase the update of universal precautions to protect both patients and nurses [21, 22].

Human resource constraints have been addressed at national and district levels with a focus on task sharing with nurses [23-29] and task shifting to community health workers (CHWs) [23-28, 30]. Integrated care models [31-39] have been introduced to improve appropriate referrals, ART initiation, coverage and retention in care. Quality improvement approaches for better care and workplace policies and programmes have been tested such as cascade and systems analyses $[15,40-46]$. Achieving the full potential of these approaches, however, requires leadership capacity development for nurses to fully engage in enabling change [47] and to address issues such as navigating professional turf, providing supportive supervision for CHWs [48-50], and shifting the organisational context for care delivery [51].

Utilising the technical knowledge and clinical experiences of nurses in the formulation of related guidelines and policies by senior decision-makers and policymakers [52-58] also requires nursing leadership. However, many of the leadership interventions to involve nurses in developing and implementing evidence-based guidelines have been undertaken in higher-income countries [59-62]. There is a paucity of studies examining ways to strengthen nursing leadership for improvements in the uptake of evidence-informed HIV care in LMICs $[24,63,64]$. Furthermore, much of the research on building leadership capacity has focused on concentrated, short-term leadership training programmes either targeted directly at nurses [65-67] or aimed at those holding management positions [68]. As Daire et al. [63] pointed out, there is an abundance of training that focuses on the cognitive aspects of leadership rather than on the action component. If nurses in LMICs are to play a more substantial role in reorienting HIV care strategies 
and workplace conditions to be more evidenceinformed, this requires action-based leadership: nurses' engagement in and capacity to lead, implement and sustain HIV care improvements [69-71]. This study focused on strengthening the leadership and policy engagement capacity of nurses to address gaps in HIV care and workplace policies in all health facilities in their health districts.

\section{Overview of study}

The primary objective of this quasi-experimental study was to determine the impact of establishing leadership hubs on HIV care by nurses. We engaged hub members in a participatory action research (PAR) process to improve the uptake of evidence-informed nursing care practices and workplace policies for HIV. This study was undertaken in four countries (Jamaica, Kenya, South Africa and Uganda) between 2008 and 2012, as part of a larger programme ${ }^{2}$ of research and capacity building [72-74]. The main quantitative study findings are described in this paper. Qualitative results are published elsewhere [9, 56, 75-77]. This study was carried out with support from the Global Health Research Initiative (GHRI), a collaborative research funding partnership of the Canadian Institutes of Health Research, the Canadian International Development Agency, Health Canada, the International Development Research Centre and the Public Health Agency of Canada.

\section{Methods}

\section{Leadership hub intervention}

District-level ${ }^{3}$ leadership hubs were established in each country with the aim of stimulating district-wide health improvements in HIV care. The theory of change underlying the study was as follows:

1. Bringing together stakeholders from different system levels to form a district leadership hub; and

2. Providing hub members with training on research and evaluation, policy engagement and leadership; and

3. Using a participatory action research approach with hubs as they reflect on research findings from their districts about HIV care and policies;

4. Will strengthen hub members' individual agency and collective capacity to plan, develop, implement and monitor district-level, evidence-informed change strategies;

5. And will thereby improve the delivery of evidenceinformed HIV care by nurses and strengthen supporting policies in district health facilities.

Indicators related to our theory of change are described in Table 1.
Although Danschroder's Consolidated Framework for Implementation Research [78] had not been published when we designed the intervention for this study, we drew heavily on some of the literature, which informed this framework, in developing the overall leadership hub approach and specific training modules. Our focus on change within organisations as well as at the district level reflects an often neglected facet of change (the interface between inner and outer organisational contexts). Our intervention was consistent with key elements of Danschroder's framework including adapting the intervention to the local context, while retaining core components; building agency of the hub members to extend and use their affiliations and power for positive change; and using an active change process aimed at both individuals and organisations.

We had several inclusion criteria specific to the composition of each hub (see Table 2). We aimed to have every leadership hub composed of members from four stakeholder groups- direct care nurses and nurse managers; researchers; decision-makers; and community representatives. This mixed composition was intended to extend the vertical networks (across system layers) of the nurses who joined the hubs and to activate districtlevel change by stimulating horizontal collaboration among hub members. Leadership hubs were designed to act as the lever for change, or enabling mechanism, that would transform enhanced capacity into action leading to policy and practice change [72, 75, 77]. This hub intervention targeted improvements in policies and patient care within health care institutions as orchestrated through a district-level change process.

One hub was established in each intervention district. We aimed for six to nine members per hub, with one person on each hub being a person living with HIV. Hub members were recruited by the country research team who approached individuals or health care organisational leads and consulted with national advisory committees, asking them to identify potential participants. Inclusion criteria for individual hub members are shown in Table 2. Hub membership was voluntary and unpaid. National advisory committees, set up specifically for the research programme, were intended to inform hub activities. Leaders of professional nursing associations, nursing councils, policy-makers and experienced academics were invited to participate on these committees.

Standard elements of the hub intervention, implemented across all four countries, are shown in Table 3. A chronology of the hub intervention and research programme data collection/analysis is illustrated in Fig. 1. A common slate of training workshops (seven) was delivered to hubs over 3 years to build skills in using research evidence to identify gaps in clinical practice and 
Table 1 Theory of change and related indicators

\begin{tabular}{|c|c|}
\hline Theory of change & Indicators \\
\hline \multirow{3}{*}{$\begin{array}{l}\text { Bring together stakeholders from different system levels to form } \\
\text { a district leadership hub }\end{array}$} & - \# of hubs established and sustained to end of project \\
\hline & - \# of hub meetings held \\
\hline & - Turnover rate of hub members \\
\hline \multirow{3}{*}{$\begin{array}{l}\text { Provide hub members with training on research and evaluation, } \\
\text { policy engagement and leadership }\end{array}$} & - Core slate of seven hub training workshops provided for hub members \\
\hline & - Completion of professional exchange visits by hubs \\
\hline & $\begin{array}{l}\text { - Mentorship and training provided as hubs develop action plans and } \\
\text { evaluation projects }\end{array}$ \\
\hline \multirow{2}{*}{$\begin{array}{l}\text { Use a participatory action research approach with hubs as they } \\
\text { reflect on research findings from their districts about HIV care } \\
\text { and policies }\end{array}$} & - Action plans and evaluation projects reflect gaps identified through research \\
\hline & $\begin{array}{l}\text { - Country-specific research findings (quantitative and qualitative) are shared } \\
\text { with hub members }\end{array}$ \\
\hline \multirow{11}{*}{$\begin{array}{l}\text { Strengthen hub members' individual agency and collective capacity } \\
\text { to plan, develop, implement and monitor district-level, } \\
\text { evidence-informed change strategies }\end{array}$} & - Hubs develop and implement action plans \\
\hline & - Hub evaluation projects successfully completed \\
\hline & - Hubs disseminate evaluation project findings to their institutions \\
\hline & - Hub members self-assessment of capacity improvements in: \\
\hline & `Leadership and team skills to improve health \\
\hline & 'Valuing policy relevance and access \\
\hline & ${ }^{\circ}$ Disseminating research findings \\
\hline & ${ }^{\circ}$ Appraising evidence and identifying gaps \\
\hline & Initiating and undertaking evaluation \\
\hline & ${ }^{\circ} \mathrm{C}$ mmunicating with decision-makers \\
\hline & $\begin{array}{l}\text { Valuing contributions from people in different roles and at different levels } \\
\text { of the health system }\end{array}$ \\
\hline $\begin{array}{l}\text { Improve delivery of evidence-informed HIV care by nurses and } \\
\text { strengthen supporting policies in district health facilities }\end{array}$ & $\begin{array}{l}\text { - Pre/post, intervention/control findings related to stigma, clinical practices } \\
\text { and workplace policies }\end{array}$ \\
\hline
\end{tabular}

Table 2 Inclusion criteria for leadership hubs

\begin{tabular}{ll}
\hline Criteria for hub composition & - Each leadership hub will have six to nine members: \\
Members of each hub will be drawn from different levels of authority and responsibility within the health system, \\
from different disciplines and from four key stakeholder groups within each of the intervention districts: \\
- Registered nurses, registered midwives, enrolled nurses and nurse managers working in hospitals or communities \\
- Researchers: junior, intermediate or senior nurse researchers \\
- Decision-makers: from the Ministry of Health; local representatives from nursing or other health professional and \\
regulatory bodies and unions \\
- Community representatives: from community groups active on HIV issues (e.g. people living with HIV, \\
grandmothers looking after AIDS-orphaned children, women's groups) \\
- Aim to have one person on each hub who is a person living with HIV or AIDS \\
- Country nationals \\
- Lived or worked in the intervention district for some time \\
- Intend to reside in intervention district for the duration of the project \\
- Involved in committees or work related to HIV care, policies and/or programmes \\
members
\end{tabular}


Table 3 Leadership hub model_-standard intervention elements for development and implementation activities Intervention development activities

- Training sessions about leadership hubs delivered to country research staff.

- Specific training topics and objectives identified by research team in consultation with leadership hub members.

- Training materials prepared for interactive workshops. These were developed and/or adapted from training materials from other sources, by research team members with expertise pertinent to topic.

- Some workshop materials piloted with research assistants of project.

- Format for hub action plan reporting developed by research team members.

- Requirements and guidance document for developing and implementing evaluation projects developed by research team members

- Objectives, format and processes for sharing and discussing quantitative and qualitative findings from research developed by research team and research assistants.

- Format for newsletter developed by research assistant in consultation with hub members.

- Format for district level communique and international newsletter developed by research team members in consultation with hub members who advised on what findings would be most pertinent to their managers.

Intervention implementation activities

- Leadership hubs established in three intervention districts in each of four LMIC countries.

- Slate of seven core training workshops delivered to hubs over 3 years to build capacity in research, policy engagement and leadership.

- Regular, ongoing mentoring of hubs (via telephone, field visits and joint hub meetings) provided by country research staff regarding development and implementation of action plans and evaluation projects.

- Research findings shared with hubs to stimulate critical reflection and action using project data from study districts. Quantitative research findings shared included stigma, and nursing clinical practices and policies related to HIV care. Qualitative research findings shared focused on the impact of HIV on nursing workforce.

- Three project communiques, produced for hubs, presented countryspecific research findings on common topics (nursing clinical practices and policies, and HIV-related stigma).

- Eight issues of an international hub newsletter produced for hubs (documented project research findings, hub evaluation project results, profiles of hubs) to encourage sharing and exchange among hubs.

- District health action plans created by each hub addressed gaps identified through research findings.

- Evaluation projects (funded through small grants from our research programme) were written, peer reviewed, revised and implemented; findings were analysed (with assistance of research assistants) and disseminated to stakeholders by all active hubs.

- Hubs participated in professional exchange visits (e.g. meetings with national and international agencies involved in HIV; exchange visits between hubs in two countries; participation in international hub teleconferences to discuss nursing strategies).

- Leaders of all active hubs participated in and presented findings from study at an international conference (World Congress on Public Health held in Ethiopia). workplace policies for their districts, using evidence generated by the research programme. The training approach was consistent with PAR processes [79] and designed to improve hubs' abilities to identify, question and take action on setting-specific health system issues, thereby empowering members as change agents [76, 77]. Through the workshops, we addressed four aspects of capacity: ability (knowledge and skills); resources (financial, material, logistics); authority (control, voice, participation); and responsibility (accountability, monitoring). Interactive discussions during the workshops and the use of local examples tailored the content to study districts in each country. Midway into the second year of each hub's life, members were provided with countryspecific baseline findings from our surveys of evidenceinformed clinical practices and workplace policies and qualitative findings about the impact of HIV on nurses and their clinical practice. In-country research assistants (RAs) encouraged hub members to interrogate and use findings to identify priority activities they could undertake and stakeholders they should engage. Hubs were trained to develop and implement action plans to address gaps identified in workplace or district policies and practices related to HIV care. Commencing in year 3, a bi-monthly project newsletter was distributed to hubs to encourage information sharing. Three country-specific communiques were prepared to share findings and implications with institutional and district-level decisionmakers.

In years 4 and 5 , we offered each hub a small grant (maximum \$1000 per project) to plan and undertake an evaluation project examining local district-level gaps in health policy or practice related to HIV nursing care. Country research teams provided mentorship and a peer review process, led by NE, provided further input to strengthen each evaluation project. Their letters of intent and subsequent proposals were formally reviewed by the research team (team members from each study country and Canada) and interns participating in the Jamaica international research internship for health system researchers (a capacity building initiative for junior researchers, also funded by the research programme). Hubs received extensive written feedback from the peer review committee, and RAs and hubs received training in how to respond to peer reviewers. Hub members obtained institutional letters of permission to undertake their projects.

Hubs received regular mentoring throughout the project at all country sites. Country RAs worked closely with hubs, supporting them through field visits and telephone calls. They coordinated hub meetings, facilitated hub training sessions and mentored hubs through the process of developing action plans, and implementing and disseminating evaluation projects. Two international 


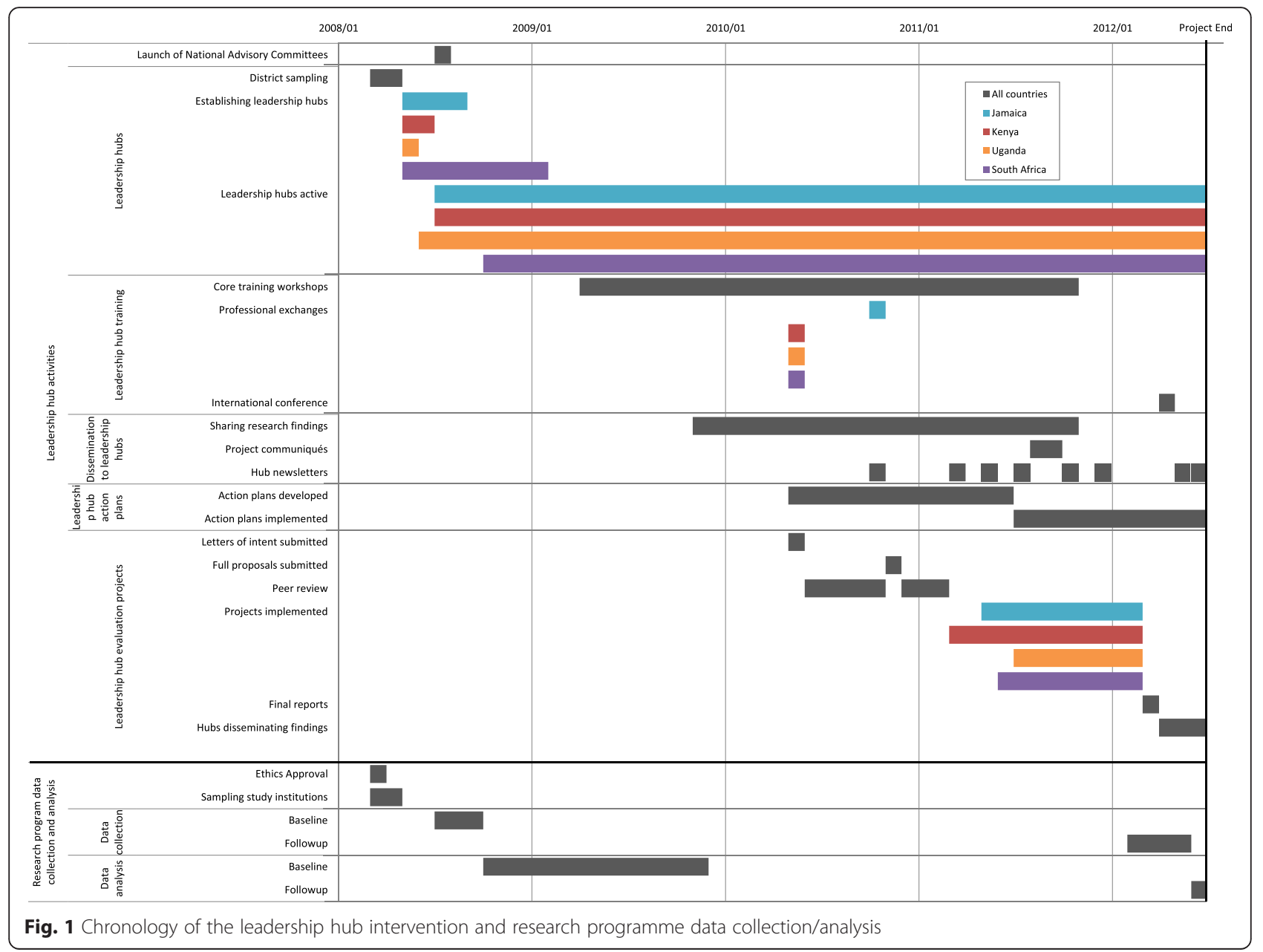

teleconferences facilitated by the Canadian programme manager brought together hubs from all countries for discussions about their evaluation projects, action plans and nursing strategies for common workplace and policy issues. The Canadian programme manager mentored country RAs throughout this process by email and Skype, encouraged peer-to-peer learning and led three face-toface refresher training sessions later in the project.

\section{Study context}

The study was conducted in countries located within the two regions most affected by HIV. In sub-Saharan Africa, which has $71 \%$ of all HIV cases worldwide, an estimated 25.8 million people are living with the disease, a prevalence of $2.8 \%$ of the total population [80, 81]. South Africa has the highest HIV prevalence in the region, at $11.2 \%$ of the total population, while Kenya and Uganda have prevalence rates of 3.8 and $3.7 \%$, respectively [80]. The Caribbean is the second most affected region of the world with an overall HIV prevalence of $1.1 \%$ (0.9-1.2 \%), and 250,000 adults and children in the region living with the disease [81]. In Jamaica, the HIV prevalence rate is $1.2 \%$.

\section{Country-specific adaptations to the intervention}

Since the hub intervention was intended to be implemented using a PAR process, it was essential that the intervention was appropriately tailored to diverse settings. Certain intervention components were intended to be adapted by each country to increase relevance to their context, an important consideration particularly in lowresource settings and given that implementation contexts and priority health issues varied greatly across countries. The proportion of hub members to be drawn from each of the four stakeholder groups was not a preset requirement. Country research teams identified members based on receptivity to engagement, availability to commit for 4 years and the local context, and built on existing institutional links between the workplaces of country project leads and other organisations. While most hub members worked at the district level, Uganda (which had one hub based in the national capital) had a hub member who was a national member of parliament. 
While the aim was to have representation of an HIVpositive person on each hub, this depended on the selfdisclosure by potential members of their HIV status; voluntary self-disclosure of HIV status was ethically essential and made it impossible to mandate a required number of HIV-positive members. The number of selfidentified HIV-positive hub members ranged from one member per hub (Jamaica) to one member per country (Kenya, Uganda and South Africa).

Flexibility was deliberately built into other intervention elements to allow country research teams to tailor to setting. While all intervention activities were undertaken in the same 4-year period, the sequencing of some activities varied by country, such as the dates that all three hubs in a given country were established (Uganda was first to achieve this, in May 2008; South Africa was last, in February 2009 due to challenges in hub member recruitment). The timing of training workshops depended on participant availability, while the timing of grant approval and rollout of hub projects depended on hub turnaround time in response to sometimes extensive peer review comments.

Communiques shared with hubs with research findings from the programme presented country-specific findings on the same topics: nursing clinical practices, HIV stigma and human resources management; Jamaica developed an additional communique (HIV training and policy). Countries tailored workshop training materials using setting-specific examples and added workshops (one to three workshops per country) based on hub learning needs and interests. The focus for hub action plans and hub evaluation projects was chosen by each hub, within the guidelines set by the project stipulating that the topic had to emerge from gaps identified by the programme's research findings and be responsive to the local health situation. Hubs could choose whether to undertake their projects on their own or jointly with another hub; in two countries (Kenya and South Africa), two hubs chose to work jointly on a project.

There were also unplanned divergences in implementation. This included the lack of a functioning national advisory committee in one country (the committee in South Africa ceased shortly after inception). In Kenya and Uganda, several hub members responded to nationally mandated redeployment of health personnel by maintaining their commitments, albeit at a distance, to their original hub (while they moved to new workplaces outside of their original intervention district, none had been redeployed to control districts). While all three hubs per country were sustained in three of the study countries, one hub (South Africa) ceased to function before the end of the project.

\section{Design}

A prospective quasi-experimental design was used, with baseline and follow-up data collection, pre- and post- establishment of the leadership hubs. Three intervention and three control districts were sampled in each country with the exception of South Africa where only intervention districts were included. ${ }^{4}$ One leadership hub was established in each intervention district. A process evaluation of the leadership hub intervention examined hub activities and self-rated changes in the capacity of hub members. Pre and post measures assessed districtwide changes in clinical practices, quality assurance, workplace policies and stigma by sampling health care institutions in intervention districts regardless of whether participants from those institutions had been involved as hub members.

\section{Multi-stage sampling}

Intervention districts were purposively selected by country directors ${ }^{5}$ with consideration given to high HIV prevalence rates, proximity to the in-country research office, variations in geographic and socioeconomic conditions (e.g. urban versus rural), and the mix of health care institutions within the district. Control districts were selected on the basis of similarities in HIV rates and the distribution of health facilities. Because we aimed to improve district-wide HIV nursing care, eligibility for participation in pre and post measures was not limited only to the health facilities employing those hub members who were health care workers. All public government health care institutions within each study district were listed and categorised using WHO criteria for level of health facility [82]. Three levels of health facilities (WHO level 3, 4 and 5 institutions ${ }^{6}$ ) were eligible for inclusion. Level 3 facilities were health centres at the sub-district level (providing primarily health promotion and prevention services); level 4 facilities were district and sub-district hospitals; and level 5 facilities were referral hospitals at the provincial or national level. We excluded level 1 and 2 facilities (community health posts and dispensaries), and we excluded facilities that were officially designated as level 3 health centres but due to staffing limitations were actually functioning as a level 1 or 2 facility.

We used stratified, multi-stage random sampling. See Table 4 describing the number of institutions and participants by WHO institution level at baseline and followup. We enrolled 16 health care institutions (as planned) in both the intervention and control districts of each country (with the exception of South Africa where there were no control districts). All national, provincial and district hospitals that met the WHO criteria were included in the sample. In Kenya, a level 5 hospital that served the three control districts was located in an adjacent province and was included in the control sample. In Uganda, two national hospitals in the same intervention district were selected. One of these national 
Table 4 Number of institutions and participants by WHO institution level at baseline and follow-up

\begin{tabular}{|c|c|c|c|c|c|c|c|c|c|c|c|c|c|c|c|c|c|c|}
\hline \multirow[t]{3}{*}{ Country $^{a}$} & \multicolumn{4}{|c|}{$\begin{array}{l}\text { National or provincial } \\
\text { hospitals (WHO level 5) }\end{array}$} & \multicolumn{4}{|c|}{$\begin{array}{l}\text { District or parish hospitals } \\
(\text { WHO level } 4)\end{array}$} & \multicolumn{4}{|c|}{ Health Centres(WHO level 3) } & \multicolumn{4}{|c|}{$\begin{array}{l}\text { Totals at baseline and } \\
\text { follow-up }\end{array}$} & \multicolumn{2}{|c|}{$\begin{array}{l}\text { Programme } \\
\text { totals }\end{array}$} \\
\hline & \multicolumn{2}{|c|}{ Baseline } & \multicolumn{2}{|c|}{ Follow-up } & \multicolumn{2}{|c|}{ Baseline } & \multicolumn{2}{|c|}{ Follow-up } & \multicolumn{2}{|c|}{ Baseline } & \multicolumn{2}{|c|}{ Follow-up } & \multicolumn{2}{|c|}{ Baseline } & \multicolumn{2}{|c|}{ Follow-up } & \multirow[b]{2}{*}{$\begin{array}{l}\text { \# of } \\
\text { instit. }\end{array}$} & \multirow[b]{2}{*}{$\begin{array}{l}\text { \# of } \\
\text { part. }\end{array}$} \\
\hline & $\begin{array}{l}\text { \# of } \\
\text { instit. }\end{array}$ & $\begin{array}{l}\text { \# of } \\
\text { part. }\end{array}$ & $\begin{array}{l}\text { \# of } \\
\text { instit. }\end{array}$ & $\begin{array}{l}\text { \# of } \\
\text { part. }\end{array}$ & $\begin{array}{l}\text { \# of } \\
\text { instit. }\end{array}$ & $\begin{array}{l}\text { \# of } \\
\text { part. }\end{array}$ & $\begin{array}{l}\text { \# of } \\
\text { instit. }\end{array}$ & $\begin{array}{l}\text { \# of } \\
\text { part. }\end{array}$ & $\begin{array}{l}\text { \# of } \\
\text { instit. }\end{array}$ & $\begin{array}{l}\text { \# of } \\
\text { part. }\end{array}$ & $\begin{array}{l}\text { \# of } \\
\text { instit. }\end{array}$ & $\begin{array}{l}\text { \# of } \\
\text { part. }\end{array}$ & $\begin{array}{l}\text { \# of } \\
\text { instit. }\end{array}$ & $\begin{array}{l}\text { \# of } \\
\text { part. }\end{array}$ & $\begin{array}{l}\text { \# of } \\
\text { instit. }\end{array}$ & $\begin{array}{l}\text { \# of } \\
\text { part. }\end{array}$ & & \\
\hline Jamaica $^{\mathrm{b}}$ & 5 & 150 & 5 & 95 & 2 & 17 & 2 & 40 & 18 & 49 & 23 & 62 & 25 & 216 & 30 & 197 & 31 & 413 \\
\hline Kenyac & 2 & 131 & 2 & 136 & 5 & 25 & 5 & 60 & 22 & 61 & 19 & 80 & 29 & 217 & 26 & 276 & 31 & 493 \\
\hline$U_{\text {Uganda }}{ }^{c}$ & 2 & 143 & 2 & 140 & 6 & 49 & 1 & 5 & 24 & 84 & 16 & 75 & 32 & 276 & 19 & 220 & 32 & 496 \\
\hline $\begin{array}{l}\text { South } \\
\text { Africa }^{d}\end{array}$ & 2 & 81 & 2 & 37 & 1 & 30 & 1 & 29 & 12 & 46 & 12 & 54 & 15 & 157 & 15 & 120 & 15 & 277 \\
\hline Total & 11 & 505 & 11 & 408 & 14 & 121 & 9 & 134 & 76 & 240 & 70 & 271 & 101 & 866 & 90 & 813 & 109 & 1679 \\
\hline
\end{tabular}

Organisation and management of health services in partner countries during the study period was centred on the district level. Level 1 and 2 facilities included community health posts and dispensaries. Level 3 facilities were health centres at the sub-district level (providing primarily health promotion and prevention services). Level 4 facilities referred to district and sub-district hospitals providing curative services. Level 5 facilities were referral hospitals at the provincial or national level. This study involved health facilities at levels 3-5

instit. institutions, part. participants

${ }^{a}$ The same institutions for all countries were sampled at baseline and follow-up when possible. Most institutions have data at both baseline and follow-up; however, some institutions only have data at either baseline or follow-up

${ }^{b}$ Increases in number from pre to post were due to increased availability of institutions at post-data collection, which were unavailable during pre-data collection

'Decreases in numbers from pre to post were due to institutional losses

${ }^{\mathrm{d}}$ South Africa had no control districts

hospitals was designated an intervention site, while the other, a specialty hospital, was assigned to the control group as it also provided services to clientele in the adjacent control district. Four or five health centres, which met WHO criteria for staff mix and functions were randomly sampled in each district. ${ }^{7}$

National, provincial and district hospitals were provided with a protocol for randomly sampling staff. All eligible staff in health centres were invited to participate. Eligibility criteria included registered or enrolled nurse, staff nurse or manager; employed in their health care setting for at least 3 months; and fluent in English.

We used the same approach to sample participants for follow-up data collection. While the same institutions were sampled at both data collection points, the identity of respondents was anonymous, and thus, we were unable to match responses to baseline and follow-up surveys for those who participated in both data collection periods. Of the institutions sampled, 82 of the 109 institutions with valid survey data, or $75.2 \%$, had at least one respondent participate at both data collection periods. Three institutions did not have valid data at either collection point.

\section{Pre and post measures}

The same self-administered questionnaire was completed at baseline and follow-up.

Socio-demographic characteristics included sex, professional designation (enrolled nurse, registered nurse), highest education level (diploma or certificate, higher level of education), current work location within the institution (community, obstetrics and/or gynaecology, other) and frequency of contact with HIV patients (daily, less often than daily).

We adapted validated instruments [62, 72, 83] to measure clinical practices, quality assurance initiatives and workplace policies. Participants were asked to report their own clinical practices and those of their nursing co-workers (12 parallel items for each scale) using a five-point Likert scale. Response options were never (1), rarely (2), sometimes (3), most of the time (4) and always (5). Ten-item scales were used to assess both workplace quality assurance initiatives and workplace policies. Response options were yes (1), no (2) or unsure (3).

We assessed two dimensions of HIV stigma and discrimination [84]: stigmatising by nurses against people with HIV (10 items) and stigmatising by co-workers and the community against nurses who provide care to people with HIV (9 items). Responses were captured using a four-point scale: never (1), once or twice (2), several times (3) and most of the time (4).

\section{Data collection}

Country RAs were trained by the principal investigators (NE, DK, EK) and project manager (SR) through a 1week intensive session. Research staff were introduced to the protocol and to PAR, taught how to conduct field sampling and assess eligibility of health care institutions and participants, instructed on how to obtain consent and trained to use all data collection measures [77]. Prior to follow-up data collection, an updated field guide was developed and refresher training held. Day-to-day supervision of RAs was provided by country directors. 


\section{Data analysis of pre and post measures}

Data were entered in an Excel database and cleaned by RAs at each country site. RAs in Jamaica and Kenya completed preliminary data analysis under the direction of the principal investigators. Final analysis using SPSS [85] and the $\mathrm{R}$ statistical programme [86] was undertaken with the assistance of a statistician who worked with the Canadian principal investigator (NE). Data analysis steps are shown in Fig. 2.

\section{Descriptive and bivariate analysis}

Descriptive analyses were used to initially examine data and to assess response patterns. A Pearson chi-square was used to compare socio-demographic characteristics of respondents in intervention and control districts at baseline and follow-up.

Several items were mistakenly excluded from one or more countries' pre-intervention questionnaires. Consequently, we discarded one item from each of the clinical assessment scales and four items from both the work place policies and quality assurance scales. We then conducted confirmatory factor analysis on these four scales and determined that a one-factor solution was optimal for each. Confirmatory factor analysis on the stigma scales yielded the two-factor structure reported in the literature [84].

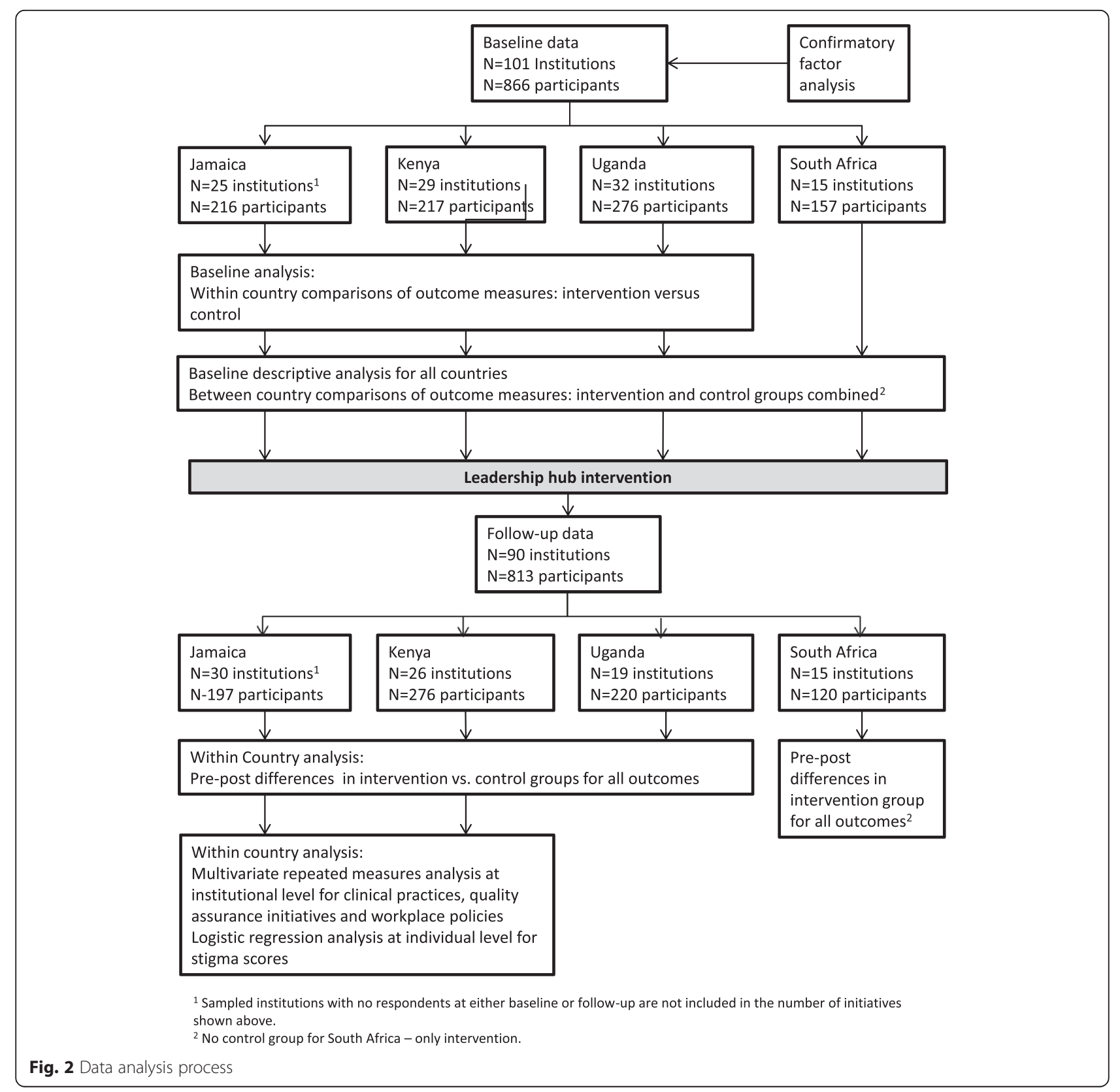


As recommended [84], we analysed scores on the stigma sub-scales in two ways, using the standardised mean score (ranging from 0 to 1 ) and a dichotomised score (never (0) versus one or more (1)). For clinical practice scores, we collapsed and recoded responses to the 11 items as never, rarely or sometimes (0), versus most of the time or always (1) and computed a standardised mean score (ranging from 0 to 1 ) for both scales. For workplace polices and quality assurance measures, we retained six items from each scale and compared yes (1) versus no or unsure (0) responses. If someone had more than one missing value, the entire response for that scale was deemed to be missing; otherwise, the missing item value was imputed using a means score imputation procedure.

Inter-country differences in baseline mean scores were assessed for all scales, with data from respondents in intervention and control groups combined, using ANOVA and post hoc testing (Tukey's HSD and Scheffe's tests). We used a paired $t$ test to compare respondents' scores on the two stigma sub-scales and on quality assurance and workplace policies.

Within-country, pre versus post differences in outcomes between intervention and control groups for Jamaica, Kenya and Uganda, were assessed using the Mantel Haenszel chi-square (for dichotomised stigma scores) and independent $t$ tests on the pre-post differences in mean scores between intervention and control groups (for all other measures). For South Africa, which had no control group, pre-post differences were compared using a Pearson chi-square and independent $t$ test.

\section{Multivariate analysis}

Multivariate analysis was completed for Kenya and Jamaica. Uganda was excluded due to a large amount of missing data for district hospitals at follow-up. South Africa was excluded as there was no control group.

Stigma measures were analysed at the individual level, using a fixed effects logistic model. We analysed other outcomes using a repeated measures model and aggregated the data by institutions as this better met the assumptions of normality. This yielded one response for each institution and period. Institutions with surveys from only one period were discarded. Precision weights based on the sample size were used to account for varying numbers of surveys from different institutions and periods.

Common parameters for all models were (a) WHO institution (national/provincial, district and health centre); (b) intervention group (control and intervention, ignoring period); (c) period (pre (baseline) and post (follow-up)); and (d) intervention period, which had one nonzero value for any additional change in the control districts in the post period over what would occur if intervention and period operated independently.

\section{Process evaluation of leadership hubs Data collection}

The characteristics of hub members and composition of hubs were documented by RAs in annual progress reports. The number and content of hub meetings and training sessions was captured from bi-monthly structured reports completed by RAs. Near the end of the project, each hub member was asked to rate their capacity (pre and post hub experience) on seven skill dimensions using a 10 -point Likert scale ( 1 = low capacity, 10 = high capacity).

\section{Data analysis}

Turnover rates in hub membership were estimated using standard labour force methods [87] to assess period turnover: $L /[(N(i)+N(f)) / 2]$, where $L=$ number of hub members who left during the period; $N(i)=$ number of hub members at the beginning of the period; and $N(f)=$ number of hub members at the end of the period. Membership counts were determined for the beginning and end of each period using information in bi-monthly hub reports. At follow-up, hub members were categorised as active if they were listed as contributors to the final evaluation project reports.

Average mean scores for each capacity dimension were calculated. Pre-post differences were compared using a paired $t$ test.

\section{Results}

\section{Leadership hubs}

At follow-up, leadership hubs averaged 8.4 members per hub; a total of 167 members participated in the hubs over the course of the intervention period. Over half (58.9\%) of hub members were direct care nurses and nurse managers; $11 \%$ were researchers; $31.5 \%$ were decision-makers; and $21.9 \%$ were community representatives. The majority of hub members came from nonsampled health institutions $(49.1 \%)$ or from other workplaces or the community (22.2\%). The remainder (28.7\%) came from the district health institutions sampled for pre and post measures. Over one third (35.9\%) of sampled institutions in intervention districts had hub member representation; Jamaica had the largest portion of hub members $(57.1 \%)$ from sampled institutions. In six of the hubs, members included one person selfdisclosed as living with HIV. Table 5 describes the membership characteristics of leadership hubs by country.

\section{Sample for pre and post measures}

A total of 101 and 90 health care institutions participated at baseline and follow-up, respectively (response 
Table 5 Membership and characteristics of leadership hubs, 2008-2012

\begin{tabular}{|c|c|c|c|c|c|}
\hline Hub characteristics and functions & Jamaica & Kenya & Uganda & South Africa & All countries \\
\hline $\begin{array}{l}\text { Average number of years hubs in each country that were } \\
\text { operational during programme }\end{array}$ & 3.9 & 4.0 & 4.1 & 3.3 & 3.8 \\
\hline Number of hubs operational at follow-up & $3 / 3$ & $3 / 3$ & $3 / 3$ & $2 / 3$ & $11 / 12$ \\
\hline Total number of hub members over hub lifespan & 28 & 58 & 33 & 48 & 167 \\
\hline \multicolumn{6}{|l|}{$\begin{array}{l}\text { Average number of members per hub ( } n=\text { total number of hub } \\
\text { members from all hubs in country) }\end{array}$} \\
\hline At baseline & $7.0(n=21)$ & $13.7(n=41)$ & $7.0(n=21)$ & $9.0(n=27)$ & $9.1(n=110)$ \\
\hline At follow-up ${ }^{d}$ & $5.3(n=16)$ & $9.7(n=29)$ & $6.7(n=20)$ & $13.5(n=27)^{\mathrm{a}}$ & $8.4(n=92)^{a}$ \\
\hline $\begin{array}{l}\text { Percentage of hub members at follow-up actively participating } \\
\text { in hub activities }\end{array}$ & $100 \%$ & $69.0 \%$ & $95.0 \%$ & $66.7 \%$ & $79.3 \%$ \\
\hline \multicolumn{6}{|l|}{$\begin{array}{l}\text { Composition of hub members actively participating in hub } \\
\text { activities at follow-up }{ }^{b}\end{array}$} \\
\hline Nurses & $12(75.0 \%)$ & $17(85.0 \%)$ & 7 (36.8 \%) & 7 (38.9 \%) & $43(58.9 \%)$ \\
\hline Decision-makers & $0(0.0 \%)$ & $10(50.0 \%)$ & $7(36.8 \%)$ & $6(33.3 \%)$ & $23(31.5 \%)$ \\
\hline Researchers & $3(18.8 \%)$ & $0(0.0 \%)$ & $5(26.3 \%)$ & $0(0.0 \%)$ & $8(11.0 \%)$ \\
\hline Community representatives & $1(6.3 \%)$ & $3(15.0 \%)$ & $6(31.6 \%)$ & $4(22.2 \%)$ & $14(19.2 \%)$ \\
\hline \multicolumn{6}{|l|}{ Leadership hub turnover rate ${ }^{c}$} \\
\hline $2008-2009^{d}$ & $0.0 \%$ & $27.3 \%$ & $8.0 \%$ & $9.4 \%$ & $13.5 \%$ \\
\hline 2010 & $34.1 \%$ & $2.8 \%$ & $10.9 \%$ & $10.8 \%$ & $12.4 \%$ \\
\hline 2011 & $0.0 \%$ & $24.6 \%$ & $0.0 \%$ & $6.3 \%$ & $10.0 \%$ \\
\hline $2012^{d, e}$ & $27.0 \%$ & $0.0 \%$ & $0.0 \%$ & $0.0 \%$ & $5.0 \%$ \\
\hline Average over hub lifespan $95 \%$ confidence interval & $15.3 \pm 15.2 \%$ & $13.7 \pm 12.1 \%$ & $4.7 \pm 4.7 \%$ & $6.6 \pm 4.1 \%$ & $10.2 \pm 3.2 \%$ \\
\hline $\begin{array}{l}\text { Percentage of hub members at follow-up that were in the hub } \\
\text { for its total duration }\end{array}$ & $81.3 \%(13 / 16)$ & $65.5 \%(19 / 29)$ & $65.0 \%(13 / 20)$ & $77.8 \%(21 / 27)$ & $71.7 \%(66 / 92)$ \\
\hline $\begin{array}{l}\text { Number of sampled intervention institutions with hub member } \\
\text { representatives engaged in the hub evaluation projects }\end{array}$ & 4 & 8 & 2 & 3 & 17 \\
\hline \multicolumn{6}{|l|}{ Percentage of hub members over hub lifespan from } \\
\hline Sampled institutions & $57.1 \%(16 / 28)$ & $19.0 \%(11 / 58)$ & $24.2 \%(8 / 33)$ & $27.1 \%(13 / 48)$ & $28.7 \%(48 / 167)$ \\
\hline Non-sampled institutions & $39.3 \%(11 / 28)$ & $56.9 \%(33 / 58)$ & $51.5 \%(17 / 33)$ & $43.8 \%(21 / 48)$ & $49.1 \%(82 / 167)$ \\
\hline Other workplaces or community & $3.6 \%(1 / 28)$ & $24.1 \%(14 / 58)$ & $24.2 \%(8 / 33)$ & $29.2 \%(14 / 48)$ & $22.2 \%(37 / 167)$ \\
\hline
\end{tabular}

Percentage of sampled intervention institutions with hub members representation during the hub lifespan

$$
\begin{aligned}
& \text { National or provincial hospitals } \\
& \text { District or parish hospitals } \\
& \text { Health centres } \\
& \text { Average for all institutions }
\end{aligned}
$$

Range and average number of hub members per intervention institution during the hub lifespan

Range and average number of distinct workplaces represented by hub members in each hub during hub lifespan

Number of hub meetings per country, 2008-2012

\begin{tabular}{lllll}
$100 \%(3 / 3)$ & $100 \%(1 / 1)$ & $100 \%(1 / 1)$ & $50 \%(1 / 2)$ & $85.7 \%(6 / 7)$ \\
$100 \%(1 / 1)$ & $66.7 \%(2 / 3)$ & $33.3 \%(1 / 3)$ & $0 \%(0 / 1)$ & $50.0 \%(4 / 8)$ \\
$0 \%(0 / 13)$ & $50.0 \%(6 / 12)$ & $0.0 \%(0 / 12)$ & $58.3 \%(7 / 12)$ & $26.5 \%(13 / 49)$ \\
$23.5 \%(4 / 17)$ & $56.3 \%(9 / 16)$ & $12.5 \%(2 / 16)$ & $53.3 \%(8 / 15)$ & $35.9 \%(23 / 64)$ \\
Range 0-9 & Range 0-2 & Range 0-5 & Range 0-4 & Range 0-9 \\
Average 0.9 & Average 0.7 & Average 0.5 & Average 0.9 & Average 0.8 \\
Range 2-5 & Range 8-11 & Range 3-7 & Range 8-15 & Range 2-15 \\
Average 3.3 & Average 9.7 & Average 4.7 & Average 11.7 & Average 7.4 \\
30 & 39 & 25 & 36 & 130 \\
\hline
\end{tabular}

${ }^{a}$ One of the South African hubs ceased operations at the end of 2011 so was not included in follow-up measures

${ }^{b}$ Categories are not mutually exclusive; some hub members were listed in more than one category

'Leadership hub turnover is calculated as $L /[(N(i)+N(f)) / 2]$, where $L=$ number of hub members who left during the period; $N(i)=$ number of hub members at the beginning of the period; and $N(f)=$ number of hub members at the end of the period. (Bureau of Labor Statistics, n.d.)

${ }^{\mathrm{d}}$ Since hubs were established in either 2008 or 2009 (depending on the hub and country), turnover data for 2008 and 2009 were collapsed

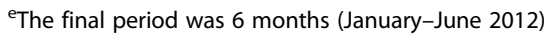


rates of 90.2 and $80.4 \%$ ). There were 866 survey respondents at baseline and 813 at follow-up. A minority of follow-up participants (ranging from $12.4 \%$ in Jamaica to $25 \%$ in South Africa) indicated that they had also completed the baseline interview. All study districts had level 3 health centres (30.4\% of the sample) but some districts also had a level 5 provincial/national hospital and/or a level 4 district hospital (54.5 and $15.2 \%$ of participants, respectively). In Uganda at follow-up, there were no participants from district hospitals (level 4 institutions) in the control group and only five in the intervention group (see Table 4).

Baseline respondents were predominantly female, and $77.2 \%$ were registered nurses. The majority of respondents $(71.7 \%)$ had at least daily contact with HIV patients. Participants had worked in their current work setting an average of 9.75 years; $49.3 \%$ of the participants were in a staff nurse position and $50.7 \%$ were managers. Kenya had the largest percentage of male respondents. South Africa had the largest proportion of registered nurses, while Jamaica had the largest proportion of enrolled nurses. The proportion of registered nurses was highest in health centres in both Jamaica and Kenya. Jamaican respondents reported significantly less daily contact with HIV patients (35.2\%) compared with other countries (over $80 \%$ ) (see Table 6 for sociodemographic characteristics of all health workers by country and by data collection period).

In all countries, there were significant differences in the composition of the sample coming from different WHO institutional levels between baseline and followup, and in the three countries with control groups, between intervention and control districts. WHO institution level was associated with significant differences in baseline scores for most outcomes (clinical practices (self and peers), quality assurance and workplace policies were assessed): Jamaica (4/4), Kenya (2/4), South Africa $(4 / 4)$ and Uganda (3/4). However, the direction of these differences varied. In Jamaica, Kenya and South Africa, health centres had the highest (best) scores while, in Uganda, health centres had the lowest (worst) scores (see Table 7).

\section{Inter-country comparisons at baseline}

At baseline, Jamaica and Uganda had significantly lower (worse) clinical practice scores than either Kenya or South Africa (assessment of self and peers; $F=37.1, p<0.0001$; $F=25.1, p<0.0001$, respectively), while Uganda had significantly lower scores on workplace policies and quality assurance than other countries $(F=37.4, p<0.00001$; and $F=74.8, p<0.00001$, respectively). All four countries had significantly worse scores for quality assurance initiatives than workplace policies $(p<0.0001)$.
A comparison of scale items revealed four main practice gaps across all countries. These were as follows: assessing the knowledge of family members to prevent HIV transmission, clients' comfort in disclosing their HIV status to family members, family health needs related to HIV care; and referring family members for voluntary counselling and testing. A similar pattern was observed for related items assessing quality assurance initiatives and workplace policies.

The highest (best) score on the clinical practice scale was for the item "consistently using universal precautions to prevent HIV transmission with clients" ( $>90 \%$ for all countries). However, quality assurance initiatives to monitor either adherence to universal precautions or the occurrence of occupational exposure to HIV were more variable, ranging within country districts from 47.2 to $80.7 \%$ and 56 to $81 \%$, respectively.

At baseline, stigma scores on both sub-scales were significantly different across countries. Post hoc analysis indicated that Uganda and Kenya had worse scores on the nurses' stigmatising scale than South Africa. On the nurses being stigmatised scale, Jamaica had significantly better scores, while Uganda had significantly worse scores than comparator countries. Nurses were significantly more likely to report being stigmatised than stigmatising patients $(p<0.0001)$ in all countries except Jamaica, where the reverse relationship was found $(p=0.002)$ (see Table 8).

\section{Pre-post differences}

South Africa was the only country with a significant improvement in clinical practices from baseline to follow-up ( $p=0.0002)$ (see Table 7). There were statistically significant improvements in quality assurance and workplace policies for Jamaica and South Africa $(p=0.026$ and $p=0.001$ for quality assurance and $p=0.025$ and $p=0.031$ for workplace policies, respectively). In Jamaica, significance levels reflected slight improvements in the intervention group in combination with deteriorations in the control group. Both Kenya and Uganda experienced a significant deterioration in quality assurance scores in intervention relative to control districts from pre to post periods. In Uganda, the same significant decline was seen for workplace policies.

Using the dichotomised score for stigma, both Jamaican and Kenyan participants in intervention institutions reported a significant decrease in pre to post instances of stigmatising HIV patients compared to those in control institutions (see Table 8). Kenyan and South African nurses reported a decline in instances of being stigmatised between pre and post periods. However, in Uganda, the control group reported a significantly larger pre-post reduction in being stigmatised than the intervention 
Table 6 Socio-demographic characteristics of participants on clinical practices, quality assurance, workplace policies and stigma scales. Data included is from all participants who completed pre or post questionnaires for the listed measures. For Jamaica, Kenya and Uganda, the following within-country comparisons were calculated: intervention (pre versus post); control (pre versus post); and pre-intervention versus pre-control versus post-intervention versus post-control. For South Africa, a pre versus post comparison was included

\begin{tabular}{|c|c|c|c|c|c|c|c|c|c|c|c|c|c|c|c|c|c|c|c|c|c|c|c|c|}
\hline \multirow[b]{3}{*}{$\begin{array}{l}\text { Socio-demographic } \\
\text { characteristic }\end{array}$} & \multicolumn{7}{|c|}{ Jamaica } & \multicolumn{7}{|c|}{ Kenya } & \multicolumn{7}{|c|}{ Uganda } & \multirow{2}{*}{\multicolumn{3}{|c|}{$\frac{\text { South Africa }}{\text { Intervention }}$}} \\
\hline & \multicolumn{3}{|c|}{ Intervention } & \multicolumn{3}{|c|}{ Control } & \multirow{2}{*}{$\begin{array}{c}\text { Int vs. } \\
\text { con }^{a} \\
x^{2} \\
\text { sig }\end{array}$} & \multicolumn{3}{|c|}{ Intervention } & \multicolumn{3}{|c|}{ Control } & \multirow{2}{*}{$\begin{array}{l}\text { Int vs. } \\
\operatorname{con}^{\mathrm{a}} \\
x^{2} \\
\text { sig }\end{array}$} & \multicolumn{3}{|c|}{ Intervention } & \multicolumn{3}{|c|}{ Control } & \multirow{2}{*}{$\begin{array}{l}\text { Int vs. } \\
\text { con }^{a} \\
x^{2} \\
\text { sig }\end{array}$} & & & \\
\hline & $\begin{array}{l}\text { Pre } \\
n(\%)\end{array}$ & $\begin{array}{l}\text { Post } \\
n(\%)\end{array}$ & $\begin{array}{l}x^{2} \\
\text { sig }\end{array}$ & $\begin{array}{l}\text { Pre } \\
n(\%)\end{array}$ & $\begin{array}{l}\text { Post } \\
n(\%)\end{array}$ & $\begin{array}{l}x^{2} \\
\text { sig }\end{array}$ & & $\begin{array}{l}\text { Pre } \\
n(\%)\end{array}$ & $\begin{array}{l}\text { Post } \\
n(\%)\end{array}$ & $\begin{array}{l}X^{2} \\
\text { sig }\end{array}$ & $\begin{array}{l}\text { Pre } \\
n(\%)\end{array}$ & $\begin{array}{l}\text { Post } \\
n(\%)\end{array}$ & $\begin{array}{l}x^{2} \\
\text { sig }\end{array}$ & & $\begin{array}{l}\text { Pre } \\
n(\%)\end{array}$ & $\begin{array}{l}\text { Post } \\
n(\%)\end{array}$ & $\begin{array}{l}x^{2} \\
\text { sig }\end{array}$ & $\begin{array}{l}\text { Pre } \\
n(\%)\end{array}$ & $\begin{array}{l}\text { Post } \\
n(\%)\end{array}$ & $\begin{array}{l}X^{2} \\
\text { sig }\end{array}$ & & $\begin{array}{l}\text { Pre } \\
n(\%)\end{array}$ & $\begin{array}{l}\text { Post } \\
n(\%)\end{array}$ & $\begin{array}{l}x^{2} \\
\text { sig }\end{array}$ \\
\hline Total & 121 & 93 & - & 95 & 104 & - & - & 100 & 161 & - & 117 & 115 & - & - & 135 & 103 & - & 141 & 117 & - & - & 157 & 120 & - \\
\hline \multicolumn{25}{|l|}{ Sex } \\
\hline Female & $\begin{array}{c}119 \\
(98.3)\end{array}$ & $\begin{array}{c}92 \\
(98.9)\end{array}$ & 0.722 & $\begin{array}{c}94 \\
(98.9)\end{array}$ & $\begin{array}{c}104 \\
(100)\end{array}$ & 0.294 & 0.742 & $\begin{array}{c}79 \\
(79.0)\end{array}$ & $\begin{array}{c}137 \\
(85.1)\end{array}$ & 0.442 & $\begin{array}{c}99 \\
(84.6)\end{array}$ & $\begin{array}{c}89 \\
(77.4)\end{array}$ & 0.088 & 0.577 & $\begin{array}{c}131 \\
(97.0)\end{array}$ & $\begin{array}{c}98 \\
(95.1)\end{array}$ & 0.686 & $\begin{array}{c}128 \\
(90.8)\end{array}$ & $\begin{array}{c}103 \\
(88.0)\end{array}$ & 0.745 & 0.763 & $\begin{array}{c}148 \\
(94.3)\end{array}$ & $\begin{array}{l}108 \\
(90.0)\end{array}$ & 0.265 \\
\hline Male & $\begin{array}{c}2 \\
(1.7)\end{array}$ & $\begin{array}{c}1 \\
(1.1)\end{array}$ & & $\begin{array}{c}1 \\
(1.1)\end{array}$ & $\begin{array}{c}0 \\
(0)\end{array}$ & & & $\begin{array}{c}18 \\
(18.0)\end{array}$ & $\begin{array}{c}24 \\
(14.9)\end{array}$ & & $\begin{array}{c}16 \\
(13.7)\end{array}$ & $\begin{array}{c}26 \\
(22.6)\end{array}$ & & & $\begin{array}{c}4 \\
(3.0)\end{array}$ & $\begin{array}{c}4 \\
(3.9)\end{array}$ & & $\begin{array}{c}13 \\
(9.2)\end{array}$ & $\begin{array}{c}12 \\
(10.3)\end{array}$ & & & $\begin{array}{c}9 \\
(5.7)\end{array}$ & $\begin{array}{c}11 \\
(9.2)\end{array}$ & \\
\hline Missing ${ }^{b}$ & $\begin{array}{c}0 \\
(0)\end{array}$ & $\begin{array}{c}0 \\
(0)\end{array}$ & N/A & $\begin{array}{c}0 \\
(0)\end{array}$ & $\begin{array}{c}0 \\
(0)\end{array}$ & N/A & N/A & $\begin{array}{c}3 \\
(3.0)\end{array}$ & $\begin{array}{c}0 \\
(0)\end{array}$ & N/A & $\begin{array}{c}2 \\
(1.7)\end{array}$ & $\begin{array}{c}0 \\
(0)\end{array}$ & N/A & N/A & $\begin{array}{c}0 \\
(0)\end{array}$ & $\begin{array}{c}1 \\
(1.0)\end{array}$ & N/A & $\begin{array}{c}0 \\
(0)\end{array}$ & $\begin{array}{c}2 \\
(1.7)\end{array}$ & N/A & N/A & $\begin{array}{c}0 \\
(0)\end{array}$ & $\begin{array}{c}1 \\
(0.8)\end{array}$ & N/A \\
\hline \multicolumn{25}{|l|}{ Level of health facility } \\
\hline National/provincial & $\begin{array}{c}84 \\
(69.4)\end{array}$ & $\begin{array}{c}47 \\
(50.5)\end{array}$ & 0.008 & $\begin{array}{c}66 \\
(69.5)\end{array}$ & $\begin{array}{c}48 \\
(42.1)\end{array}$ & 0.002 & N/A & $\begin{array}{c}49 \\
(49.0)\end{array}$ & $\begin{array}{c}74 \\
(46.0)\end{array}$ & 0.270 & $\begin{array}{c}82 \\
(70.1)\end{array}$ & $\begin{array}{c}62 \\
(53.9)\end{array}$ & 0.017 & N/A & $\begin{array}{c}69 \\
(51.1)\end{array}$ & $\begin{array}{c}77 \\
(74.8)\end{array}$ & 0.000 & $\begin{array}{c}74 \\
(52.5)\end{array}$ & $\begin{array}{c}63 \\
(53.8)\end{array}$ & 0.000 & N/A & $\begin{array}{c}81 \\
(51.6)\end{array}$ & $\begin{array}{c}37 \\
(30.8)\end{array}$ & 0.002 \\
\hline District/parish & $\begin{array}{c}10 \\
(8.3)\end{array}$ & $\begin{array}{c}19 \\
(20.4)\end{array}$ & & $\begin{array}{c}7 \\
(7.4)\end{array}$ & $\begin{array}{c}21 \\
(20.2)\end{array}$ & & & $\begin{array}{c}16 \\
(16.0)\end{array}$ & $\begin{array}{c}39 \\
(24.2)\end{array}$ & & $\begin{array}{c}9 \\
(7.7)\end{array}$ & $\begin{array}{c}21 \\
(18.3)\end{array}$ & & & $\begin{array}{c}24 \\
(17.8)\end{array}$ & $\begin{array}{c}5 \\
(4.9)\end{array}$ & & $\begin{array}{c}25 \\
(17.7)\end{array}$ & $\begin{array}{c}0 \\
(0)\end{array}$ & & & $\begin{array}{c}30 \\
(19.1)\end{array}$ & $\begin{array}{c}29 \\
(24.2)\end{array}$ & \\
\hline Health centre & $\begin{array}{c}27 \\
(22.3)\end{array}$ & $\begin{array}{c}27 \\
(29.1)\end{array}$ & & $\begin{array}{c}22 \\
(23.1)\end{array}$ & $\begin{array}{c}35 \\
(33.7)\end{array}$ & & & $\begin{array}{c}35 \\
(35.0)\end{array}$ & $\begin{array}{c}48 \\
(29.8)\end{array}$ & & $\begin{array}{c}26 \\
(22.2)\end{array}$ & $\begin{array}{c}32 \\
(27.8)\end{array}$ & & & $\begin{array}{c}42 \\
(31.1)\end{array}$ & $\begin{array}{c}21 \\
(20.4)\end{array}$ & & $\begin{array}{c}42 \\
(29.8)\end{array}$ & $\begin{array}{c}54 \\
(46.2)\end{array}$ & & & $\begin{array}{c}46 \\
(29.3)\end{array}$ & $\begin{array}{c}54 \\
(45.0)\end{array}$ & \\
\hline \multicolumn{25}{|l|}{ Professional designation } \\
\hline $\begin{array}{l}\text { Enrolled nurse/ } \\
\text { midwife }\end{array}$ & $\begin{array}{c}33 \\
(27.3)\end{array}$ & $\begin{array}{c}17 \\
(18.3)\end{array}$ & 0.157 & $\begin{array}{c}21 \\
(22.1)\end{array}$ & $\begin{array}{c}14 \\
(13.5)\end{array}$ & 0.123 & 0.051 & - & $\begin{array}{c}39 \\
(24.2)\end{array}$ & N/A & $\begin{array}{c}44 \\
(37.6)\end{array}$ & $\begin{array}{c}31 \\
(27.4)\end{array}$ & 0.000 & N/A & - & $\begin{array}{c}11 \\
(10.7)\end{array}$ & N/A & - & $\begin{array}{c}49 \\
(41.9)\end{array}$ & N/A & N/A & $\begin{array}{c}0 \\
(0)\end{array}$ & $\begin{array}{c}9 \\
(7.6)\end{array}$ & 0.004 \\
\hline $\begin{array}{l}\text { Registered nurse/ } \\
\text { midwife }\end{array}$ & $\begin{array}{c}88 \\
(72.7)\end{array}$ & $\begin{array}{c}73 \\
(78.5)\end{array}$ & & $\begin{array}{c}73 \\
(76.8)\end{array}$ & $\begin{array}{c}87 \\
(83.7)\end{array}$ & & & -- & $\begin{array}{c}119 \\
(74.0)\end{array}$ & & $\begin{array}{c}36 \\
(30.8)\end{array}$ & $\begin{array}{c}82 \\
(72.6)\end{array}$ & & & - & $\begin{array}{c}87 \\
(84.5)\end{array}$ & & - & $\begin{array}{c}50 \\
(42.7)\end{array}$ & & & $\begin{array}{c}102 \\
(65.0)\end{array}$ & $\begin{array}{c}109 \\
(90.8)\end{array}$ & \\
\hline Missing ${ }^{b}$ & $\begin{array}{c}0 \\
(0)\end{array}$ & $\begin{array}{c}3 \\
(3.2)\end{array}$ & N/A & $\begin{array}{c}1 \\
(1.1)\end{array}$ & $\begin{array}{c}3 \\
(2.8)\end{array}$ & N/A & N/A & $\begin{array}{c}100 \\
(100)\end{array}$ & $\begin{array}{c}3 \\
(1.8)\end{array}$ & N/A & $\begin{array}{c}37 \\
(31.6)\end{array}$ & $\begin{array}{c}2 \\
(1.7)\end{array}$ & N/A & N/A & $\begin{array}{c}135 \\
(100)\end{array}$ & $\begin{array}{c}5 \\
(4.9)\end{array}$ & N/A & $\begin{array}{c}141 \\
(100)\end{array}$ & $\begin{array}{c}18 \\
(15.4)\end{array}$ & N/A & N/A & $\begin{array}{c}55 \\
(35.0)\end{array}$ & $\begin{array}{c}2 \\
(1.6)\end{array}$ & N/A \\
\hline \multicolumn{25}{|l|}{ Highest education level } \\
\hline Diploma/certificate & $\begin{array}{c}87 \\
(72.0)\end{array}$ & $\begin{array}{c}44 \\
(47.3)\end{array}$ & 0.001 & $\begin{array}{c}65 \\
(68.4)\end{array}$ & $\begin{array}{c}65 \\
(62.5)\end{array}$ & 0.530 & 0.005 & $\begin{array}{c}53 \\
(53.0)\end{array}$ & $\begin{array}{c}137 \\
(85.1)\end{array}$ & 0.009 & $\begin{array}{c}82 \\
(70.1)\end{array}$ & $\begin{array}{c}84 \\
(73.1)\end{array}$ & 0.042 & 0.792 & $\begin{array}{c}89 \\
(65.9)\end{array}$ & $\begin{array}{c}92 \\
(89.3)\end{array}$ & 0.291 & $\begin{array}{c}69 \\
(48.9)\end{array}$ & $\begin{array}{c}101 \\
(86.3)\end{array}$ & 0.625 & 0.350 & $\begin{array}{c}81 \\
(51.6)\end{array}$ & $\begin{array}{c}84 \\
(70.0)\end{array}$ & 0.029 \\
\hline $\begin{array}{l}\text { Higher level of } \\
\text { education }\end{array}$ & $\begin{array}{c}33 \\
(27.2)\end{array}$ & $\begin{array}{c}45 \\
(48.4)\end{array}$ & & $\begin{array}{c}28 \\
(29.5)\end{array}$ & $\begin{array}{c}34 \\
(32.7)\end{array}$ & & & $\begin{array}{c}22 \\
(22.0)\end{array}$ & $\begin{array}{c}24 \\
(14.9)\end{array}$ & & $\begin{array}{c}13 \\
(11.1)\end{array}$ & $\begin{array}{c}28 \\
(24.3)\end{array}$ & & & $\begin{array}{c}14 \\
(10.4)\end{array}$ & $\begin{array}{c}9 \\
(8.7)\end{array}$ & & $\begin{array}{c}11 \\
(7.8)\end{array}$ & $\begin{array}{c}13 \\
(11.1)\end{array}$ & & & $\begin{array}{c}57 \\
(36.3)\end{array}$ & $\begin{array}{c}33 \\
(27.5)\end{array}$ & \\
\hline Missing $^{b}$ & $\begin{array}{c}1 \\
(0.8)\end{array}$ & $\begin{array}{c}4 \\
(4.3)\end{array}$ & N/A & $\begin{array}{c}2 \\
(2.1)\end{array}$ & $\begin{array}{c}5 \\
(4.8)\end{array}$ & N/A & N/A & $\begin{array}{c}25 \\
(25.0)\end{array}$ & $\begin{array}{c}0 \\
(0)\end{array}$ & N/A & $\begin{array}{c}22 \\
(18.8)\end{array}$ & $\begin{array}{c}3 \\
(2.6)\end{array}$ & N/A & N/A & $\begin{array}{c}32 \\
(23.7)\end{array}$ & $\begin{array}{c}2 \\
(1.9)\end{array}$ & N/A & $\begin{array}{c}61 \\
(43.3)\end{array}$ & $\begin{array}{c}3 \\
(2.6)\end{array}$ & N/A & N/A & $\begin{array}{c}19 \\
(12.1)\end{array}$ & $\begin{array}{c}3 \\
(2.5)\end{array}$ & N/A \\
\hline \multicolumn{25}{|c|}{ Current work location within the institution } \\
\hline Community & $\begin{array}{c}29 \\
(24.0)\end{array}$ & $\begin{array}{c}25 \\
(26.9)\end{array}$ & 0.083 & $\begin{array}{c}18 \\
(18.9)\end{array}$ & $\begin{array}{c}27 \\
(26.0)\end{array}$ & 0.027 & N/A & $\begin{array}{c}7 \\
(7.0)\end{array}$ & $\begin{array}{c}7 \\
(4.3)\end{array}$ & 0.154 & $\begin{array}{c}13 \\
(11.0)\end{array}$ & $\begin{array}{c}5 \\
(4.3)\end{array}$ & 0.003 & N/A & $\begin{array}{c}3 \\
(2.2)\end{array}$ & $\begin{array}{c}8 \\
(7.8)\end{array}$ & 0.002 & $\begin{array}{c}15 \\
(10.6)\end{array}$ & $\begin{array}{c}6 \\
(5.1)\end{array}$ & 0.197 & N/A & $\begin{array}{c}49 \\
(31.2)\end{array}$ & $\begin{array}{c}38 \\
(31.7)\end{array}$ & 0.988 \\
\hline
\end{tabular}


Table 6 Socio-demographic characteristics of participants on clinical practices, quality assurance, workplace policies and stigma scales. Data included is from all participants who completed pre or post questionnaires for the listed measures. For Jamaica, Kenya and Uganda, the following within-country comparisons were calculated: intervention (pre versus post); control (pre versus post); and pre-intervention versus pre-control versus post-intervention versus post-control. For South Africa, a pre versus post comparison was included (Continued)

\begin{tabular}{|c|c|c|c|c|c|c|c|c|c|c|c|c|c|c|c|c|c|c|c|c|c|c|c|c|}
\hline $\begin{array}{l}\text { Obstetrics/ } \\
\text { gynaecology }\end{array}$ & $\begin{array}{c}6 \\
(5.0)\end{array}$ & $\begin{array}{c}12 \\
(12.9)\end{array}$ & & $\begin{array}{c}4 \\
(4.2)\end{array}$ & $\begin{array}{c}14 \\
(13.5)\end{array}$ & & & $\begin{array}{c}7 \\
(7.0)\end{array}$ & $\begin{array}{c}23 \\
(14.3)\end{array}$ & & $\begin{array}{c}20 \\
(17.1)\end{array}$ & $\begin{array}{c}7 \\
(6.1)\end{array}$ & & & $\begin{array}{c}36 \\
(26.7)\end{array}$ & $\begin{array}{c}11 \\
(10.7)\end{array}$ & & $\begin{array}{c}5 \\
(3.5)\end{array}$ & $\begin{array}{c}7 \\
(6.0)\end{array}$ & & & $\begin{array}{c}18 \\
(11.5)\end{array}$ & $\begin{array}{c}14 \\
(11.7)\end{array}$ & \\
\hline Other ${ }^{\mathrm{c}}$ & $\begin{array}{c}84 \\
(69.3)\end{array}$ & $\begin{array}{c}55 \\
(59.1)\end{array}$ & & $\begin{array}{c}70 \\
(73.7)\end{array}$ & $\begin{array}{c}62 \\
(59.6)\end{array}$ & & & $\begin{array}{c}84 \\
(84.0)\end{array}$ & $\begin{array}{c}130 \\
(80.7)\end{array}$ & & $\begin{array}{c}83 \\
(71.0)\end{array}$ & $\begin{array}{c}103 \\
(89.6)\end{array}$ & & & $\begin{array}{c}96 \\
(71.1)\end{array}$ & $\begin{array}{c}83 \\
(80.6)\end{array}$ & & $\begin{array}{c}118 \\
(83.7)\end{array}$ & $\begin{array}{c}101 \\
(86.3)\end{array}$ & & & $\begin{array}{c}87 \\
(55.4)\end{array}$ & $\begin{array}{c}65 \\
(54.2)\end{array}$ & \\
\hline Missing $^{\mathrm{b}}$ & $\begin{array}{c}2 \\
(1.7)\end{array}$ & $\begin{array}{c}1 \\
(1.1)\end{array}$ & N/A & $\begin{array}{c}3 \\
(3.2)\end{array}$ & $\begin{array}{c}1 \\
(1.0)\end{array}$ & N/A & N/A & $\begin{array}{c}2 \\
(2.0)\end{array}$ & $\begin{array}{c}1 \\
(0.7)\end{array}$ & N/A & $\begin{array}{c}1 \\
(0.9)\end{array}$ & $\begin{array}{l}0 \\
(0)\end{array}$ & N/A & N/A & $\begin{array}{c}0 \\
(0)\end{array}$ & $\begin{array}{c}1 \\
(0.9)\end{array}$ & N/A & $\begin{array}{c}3 \\
(2.1)\end{array}$ & $\begin{array}{c}3 \\
(2.6)\end{array}$ & N/A & N/A & $\begin{array}{c}3 \\
(1.9)\end{array}$ & $\begin{array}{c}3 \\
(2.5)\end{array}$ & N/A \\
\hline \multicolumn{25}{|c|}{ Contact with patients/clients with HIV or AIDS } \\
\hline Daily & $\begin{array}{c}51 \\
(42.1)\end{array}$ & $\begin{array}{c}37 \\
(39.8)\end{array}$ & 0.633 & $\begin{array}{c}23 \\
(24.2)\end{array}$ & $\begin{array}{c}33 \\
(31.7)\end{array}$ & 0.206 & 0.703 & $\begin{array}{c}91 \\
(91.0)\end{array}$ & $\begin{array}{c}146 \\
(90.7)\end{array}$ & 0.561 & $\begin{array}{c}94 \\
(80.3)\end{array}$ & $\begin{array}{c}98 \\
(85.2)\end{array}$ & 0.674 & 0.588 & $\begin{array}{c}107 \\
(79.3)\end{array}$ & $\begin{array}{c}68 \\
(66.0)\end{array}$ & 0.022 & $\begin{array}{c}114 \\
(80.9)\end{array}$ & $\begin{array}{c}75 \\
(64.1)\end{array}$ & 0.002 & 0.000 & $\begin{array}{c}136 \\
(86.6)\end{array}$ & $\begin{array}{c}109 \\
(90.8)\end{array}$ & 0.556 \\
\hline $\begin{array}{l}\text { Less often than } \\
\text { daily }^{\mathrm{d}}\end{array}$ & $\begin{array}{c}65 \\
(53.7)\end{array}$ & $\begin{array}{c}54 \\
(58.1)\end{array}$ & & $\begin{array}{c}71 \\
(74.7)\end{array}$ & $\begin{array}{c}68 \\
(65.4)\end{array}$ & & & $\begin{array}{c}9 \\
(9.0)\end{array}$ & $\begin{array}{c}11 \\
(6.8)\end{array}$ & & $\begin{array}{c}19 \\
(16.2)\end{array}$ & $\begin{array}{c}17 \\
(14.8)\end{array}$ & & & $\begin{array}{c}27 \\
(20.0)\end{array}$ & $\begin{array}{c}34 \\
(33.0)\end{array}$ & & $\begin{array}{c}25 \\
(17.7)\end{array}$ & $\begin{array}{c}40 \\
(34.2)\end{array}$ & & & $\begin{array}{c}16 \\
(10.2)\end{array}$ & $\begin{array}{c}10 \\
(8.3)\end{array}$ & \\
\hline Missing ${ }^{\mathrm{b}}$ & $\begin{array}{c}5 \\
(4.1)\end{array}$ & $\begin{array}{c}2 \\
(2.2)\end{array}$ & N/A & $\begin{array}{c}1 \\
(1.1)\end{array}$ & $\begin{array}{c}3 \\
(2.9)\end{array}$ & N/A & N/A & $\begin{array}{c}0 \\
(0)\end{array}$ & $\begin{array}{c}4 \\
(2.5)\end{array}$ & N/A & $\begin{array}{c}4 \\
(3.4)\end{array}$ & $\begin{array}{l}0 \\
(0)\end{array}$ & N/A & N/A & $\begin{array}{c}1 \\
(0.7)\end{array}$ & $\begin{array}{c}1 \\
\text { (1.0) }\end{array}$ & N/A & $\begin{array}{c}2 \\
(1.4)\end{array}$ & $\begin{array}{c}2 \\
(1.7)\end{array}$ & N/A & N/A & $\begin{array}{c}5 \\
(3.2)\end{array}$ & $\begin{array}{c}1 \\
(0.8)\end{array}$ & N/A \\
\hline
\end{tabular}

vs. versus

alnt vs. con comparison is a Mantel Haenszel chi-square statistics; unable to perform for South Africa due to no control group; unable to perform for health facility level and work location due to more than two distinct variables

${ }^{b}$ Missing data was not included in calculations of significance levels

cIncludes accident/emergency/casualty, medical/surgical, outpatient/ambulatory car, operating theatre, intensive care unit or other as indicated by participants

${ }^{\mathrm{d}}$ Weekly, monthly, several times per year or never 
Table 7 Outcome measures for the clinical practice—self, clinical practice_-peers, quality assurance and workplace policies scales. For Jamaica, Kenya and Uganda, the following within-country comparisons were calculated: pre (intervention versus control); and pre-intervention versus pre-control versus post-intervention versus post-control. For South Africa, a pre versus post comparison was included

\begin{tabular}{|c|c|c|c|c|c|c|c|c|c|c|c|c|c|c|c|c|c|c|}
\hline \multirow[t]{3}{*}{ Scale } & & \multicolumn{5}{|c|}{ Jamaica } & \multicolumn{5}{|c|}{ Kenya } & \multicolumn{5}{|c|}{ Uganda } & \multirow{2}{*}{\multicolumn{2}{|c|}{$\begin{array}{l}\text { South Africa } \\
\text { Intervention }\end{array}$}} \\
\hline & & \multirow{2}{*}{$\begin{array}{l}\text { Pre (int. } \\
\text { vs. con.) }\end{array}$} & \multicolumn{2}{|c|}{ Intervention } & \multicolumn{2}{|c|}{ Control } & \multirow{2}{*}{$\begin{array}{l}\text { Pre (int. } \\
\text { vs con.) }\end{array}$} & \multicolumn{2}{|c|}{ Intervention } & \multicolumn{2}{|c|}{ Control } & \multirow{2}{*}{$\begin{array}{l}\text { Pre (int. } \\
\text { vs con.) }\end{array}$} & \multicolumn{2}{|c|}{ Intervention } & \multicolumn{2}{|c|}{ Control } & & \\
\hline & & & Pre & Post & Pre & Post & & Pre & Post & Pre & Post & & Pre & Post & Pre & Post & Pre & Post \\
\hline Total & & 216 & 121 & 93 & 95 & 104 & 217 & 100 & 161 & 117 & 115 & 276 & 135 & 103 & 141 & 117 & 157 & 120 \\
\hline \multirow{5}{*}{$\begin{array}{l}\text { Clinical } \\
\text { practices_self }\end{array}$} & Number & 205 & 115 & 89 & 90 & 97 & 206 & 97 & 160 & 109 & 113 & 270 & 135 & 99 & 135 & 117 & 155 & 117 \\
\hline & Missing & 11 & 6 & 4 & 5 & 7 & 11 & 3 & 1 & 8 & 2 & 6 & 0 & 4 & 6 & 0 & 2 & 3 \\
\hline & $\mu(\mathrm{SD})$ & $\begin{array}{c}0.46 \\
(0.26)\end{array}$ & $\begin{array}{c}0.44 \\
(0.24)\end{array}$ & $\begin{array}{c}0.42 \\
(0.25)\end{array}$ & $\begin{array}{c}0.50 \\
(0.28)\end{array}$ & $\begin{array}{c}0.47 \\
(0.25)\end{array}$ & $\begin{array}{c}0.71 \\
(0.24)\end{array}$ & $\begin{array}{c}0.70 \\
(0.25)\end{array}$ & $\begin{array}{c}0.76 \\
(0.25)\end{array}$ & $\begin{array}{c}0.71 \\
(0.24)\end{array}$ & $\begin{array}{c}0.73 \\
(0.24)\end{array}$ & $\begin{array}{c}0.56 \\
(0.24)\end{array}$ & $\begin{array}{c}0.59 \\
(0.24)\end{array}$ & $\begin{array}{c}0.64 \\
(0.28)\end{array}$ & $\begin{array}{c}0.53 \\
(0.24)\end{array}$ & $\begin{array}{c}0.56 \\
(0.28)\end{array}$ & $\begin{array}{c}0.67 \\
(0.29)\end{array}$ & $\begin{array}{c}0.78 \\
(0.24)\end{array}$ \\
\hline & $95 \% \mathrm{Cl}$ & $\begin{array}{c}0.43- \\
0.50\end{array}$ & $\begin{array}{c}0.40- \\
0.48\end{array}$ & $\begin{array}{c}0.37- \\
0.48\end{array}$ & $\begin{array}{c}0.44- \\
0.56\end{array}$ & $\begin{array}{c}0.42- \\
0.52\end{array}$ & $\begin{array}{l}0.67- \\
0.74\end{array}$ & $\begin{array}{c}0.65- \\
0.75\end{array}$ & $\begin{array}{c}0.72- \\
0.80\end{array}$ & $\begin{array}{l}0.67- \\
0.76\end{array}$ & $\begin{array}{c}0.69- \\
0.77\end{array}$ & $\begin{array}{c}0.53- \\
0.58\end{array}$ & $\begin{array}{c}0.55- \\
0.63\end{array}$ & $\begin{array}{c}0.58- \\
0.69\end{array}$ & $\begin{array}{l}0.48- \\
0.57\end{array}$ & $\begin{array}{c}0.51- \\
0.61\end{array}$ & $\begin{array}{l}0.62- \\
0.72\end{array}$ & $\begin{array}{l}0.73- \\
0.82\end{array}$ \\
\hline & $p$ value ${ }^{a}$ & 0.121 & & \multicolumn{2}{|c|}{0.8831} & & \multicolumn{2}{|l|}{0.809} & \multicolumn{2}{|c|}{0.3988} & \multicolumn{3}{|c|}{0.038} & \multicolumn{2}{|c|}{0.7663} & & \multicolumn{2}{|c|}{0.002} \\
\hline \multirow{5}{*}{$\begin{array}{l}\text { Clinical } \\
\text { practices_peers }\end{array}$} & Number & 197 & 112 & 83 & 85 & 95 & 209 & 98 & 156 & 111 & 111 & 273 & 135 & 99 & 138 & 117 & 153 & 117 \\
\hline & Missing & 19 & 9 & 10 & 10 & 9 & 8 & 2 & 5 & 6 & 4 & 3 & 0 & 4 & 3 & 0 & 4 & 3 \\
\hline & $\mu(\mathrm{SD})$ & $\begin{array}{c}0.54 \\
(0.29)\end{array}$ & $\begin{array}{c}0.51 \\
(0.29)\end{array}$ & $\begin{array}{c}0.48 \\
(0.28)\end{array}$ & $\begin{array}{c}0.58 \\
(0.28)\end{array}$ & $\begin{array}{c}0.53 \\
(0.30)\end{array}$ & $\begin{array}{c}0.73 \\
(0.25)\end{array}$ & $\begin{array}{c}0.76 \\
(0.24)\end{array}$ & $\begin{array}{c}0.81 \\
(0.25)\end{array}$ & $\begin{array}{c}0.71 \\
(0.25)\end{array}$ & $\begin{array}{c}0.76 \\
(0.25)\end{array}$ & $\begin{array}{c}0.60 \\
(0.24)\end{array}$ & $\begin{array}{c}0.63 \\
(0.24)\end{array}$ & $\begin{array}{c}0.63 \\
(0.30)\end{array}$ & $\begin{array}{c}0.57 \\
(0.24)\end{array}$ & $\begin{array}{c}0.65 \\
(0.29)\end{array}$ & $\begin{array}{c}0.72 \\
(0.30)\end{array}$ & $\begin{array}{c}0.79 \\
(0.27)\end{array}$ \\
\hline & $95 \% \mathrm{Cl}$ & $\begin{array}{c}0.50- \\
0.58\end{array}$ & $\begin{array}{c}0.46- \\
0.57\end{array}$ & $\begin{array}{c}0.42- \\
0.54\end{array}$ & $\begin{array}{l}0.52- \\
0.65\end{array}$ & $\begin{array}{c}0.45- \\
0.58\end{array}$ & $\begin{array}{l}0.70- \\
0.77\end{array}$ & $\begin{array}{l}0.71- \\
0.81\end{array}$ & $\begin{array}{c}0.77- \\
0.85\end{array}$ & $\begin{array}{c}0.67- \\
0.76\end{array}$ & $\begin{array}{l}0.71- \\
0.81\end{array}$ & $\begin{array}{c}0.57- \\
0.63\end{array}$ & $\begin{array}{c}0.59- \\
0.67\end{array}$ & $\begin{array}{c}0.57- \\
0.69\end{array}$ & $\begin{array}{c}0.53- \\
0.61\end{array}$ & $\begin{array}{c}0.59- \\
0.70\end{array}$ & $\begin{array}{l}0.68- \\
0.77\end{array}$ & $\begin{array}{c}0.74- \\
0.83\end{array}$ \\
\hline & $p$ value $^{a}$ & 0.086 & & \multicolumn{2}{|c|}{0.5527} & & \multicolumn{2}{|l|}{0.229} & \multicolumn{2}{|c|}{0.7896} & & \multicolumn{2}{|l|}{0.036} & \multicolumn{2}{|c|}{0.1199} & & \multicolumn{2}{|c|}{0.098} \\
\hline Quality & Number & 210 & 116 & 92 & 94 & 101 & 210 & 99 & 161 & 111 & 113 & 268 & 133 & 102 & 135 & 116 & 154 & 118 \\
\hline & Missing & 6 & 5 & 1 & 1 & 3 & 7 & 1 & 0 & 6 & 2 & 8 & 2 & 1 & 6 & 1 & 3 & 2 \\
\hline & $\mu(\mathrm{SD})$ & $\begin{array}{c}0.71 \\
(0.28)\end{array}$ & $\begin{array}{c}0.67 \\
(0.29)\end{array}$ & $\begin{array}{c}0.69 \\
(0.30)\end{array}$ & $\begin{array}{c}0.76 \\
(0.25)\end{array}$ & $\begin{array}{c}0.67 \\
(0.30)\end{array}$ & $\begin{array}{c}0.72 \\
(0.30)\end{array}$ & $\begin{array}{c}0.77 \\
(0.29)\end{array}$ & $\begin{array}{c}0.82 \\
(0.21)\end{array}$ & $\begin{array}{c}0.67 \\
(0.31)\end{array}$ & $\begin{array}{c}0.81 \\
(0.24)\end{array}$ & $\begin{array}{c}0.49 \\
(0.29)\end{array}$ & $\begin{array}{c}0.52 \\
(0.31)\end{array}$ & $\begin{array}{c}0.56 \\
(0.30)\end{array}$ & $\begin{array}{c}0.45 \\
(0.27)\end{array}$ & $\begin{array}{c}0.74 \\
(0.26)\end{array}$ & $\begin{array}{c}0.72 \\
(0.31)\end{array}$ & $\begin{array}{c}0.84 \\
(0.22)\end{array}$ \\
\hline & $95 \% \mathrm{Cl}$ & $\begin{array}{l}0.67- \\
0.75\end{array}$ & $\begin{array}{c}0.61- \\
0.72\end{array}$ & $\begin{array}{c}0.63- \\
0.75\end{array}$ & $\begin{array}{c}0.70- \\
0.80\end{array}$ & $\begin{array}{c}0.61- \\
0.73\end{array}$ & $\begin{array}{l}0.68- \\
0.76\end{array}$ & $\begin{array}{c}0.72- \\
0.83\end{array}$ & $\begin{array}{l}0.78- \\
0.85\end{array}$ & $\begin{array}{c}0.62- \\
0.73\end{array}$ & $\begin{array}{c}0.77- \\
0.86\end{array}$ & $\begin{array}{c}0.45- \\
0.52\end{array}$ & $\begin{array}{c}0.47- \\
0.57\end{array}$ & $\begin{array}{c}0.50- \\
0.62\end{array}$ & $\begin{array}{c}0.41- \\
0.50\end{array}$ & $\begin{array}{c}0.70- \\
0.79\end{array}$ & $\begin{array}{l}0.67- \\
0.77\end{array}$ & $\begin{array}{l}0.80- \\
0.88\end{array}$ \\
\hline & $p$ value $^{a}$ & 0.023 & & & & & 0.016 & & & & & 0.069 & & & & & & \\
\hline Workplace & Number & 208 & 115 & 92 & 93 & 98 & 210 & 100 & 159 & 110 & 114 & 271 & 133 & 101 & 138 & 115 & 153 & 119 \\
\hline polıcles & Missing & 8 & 6 & 1 & 2 & 6 & 7 & 0 & 2 & 7 & 1 & 5 & 2 & 2 & 3 & 2 & 4 & 1 \\
\hline & $\mu(\mathrm{SD})$ & $\begin{array}{l}0.80 \\
(20)\end{array}$ & $\begin{array}{c}0.78 \\
(0.22)\end{array}$ & $\begin{array}{c}0.81 \\
(0.21)\end{array}$ & $\begin{array}{c}0.84 \\
(0.19)\end{array}$ & $\begin{array}{c}0.77 \\
(0.21)\end{array}$ & $\begin{array}{c}0.85 \\
(0.20)\end{array}$ & $\begin{array}{c}0.89 \\
(0.16)\end{array}$ & $\begin{array}{c}0.86 \\
(0.17)\end{array}$ & $\begin{array}{c}0.82 \\
(0.27)\end{array}$ & $\begin{array}{c}0.87 \\
(0.18)\end{array}$ & $\begin{array}{c}0.56 \\
(0.32)\end{array}$ & $\begin{array}{c}0.65 \\
(0.32)\end{array}$ & $\begin{array}{c}0.62 \\
(0.31)\end{array}$ & $\begin{array}{c}0.47 \\
(0.31)\end{array}$ & $\begin{array}{c}0.76 \\
(0.26)\end{array}$ & $\begin{array}{c}0.82 \\
(0.22)\end{array}$ & $\begin{array}{c}0.87 \\
(0.17)\end{array}$ \\
\hline & $95 \% \mathrm{Cl}$ & $\begin{array}{c}0.78- \\
0.83\end{array}$ & $\begin{array}{c}0.74- \\
0.82\end{array}$ & $\begin{array}{c}0.77- \\
0.85\end{array}$ & $\begin{array}{c}0.80- \\
0.88\end{array}$ & $\begin{array}{c}0.73- \\
0.81\end{array}$ & $\begin{array}{c}0.82- \\
0.88\end{array}$ & $\begin{array}{c}0.86- \\
0.93\end{array}$ & $\begin{array}{c}0.83- \\
0.88\end{array}$ & $\begin{array}{c}0.77- \\
0.86\end{array}$ & $\begin{array}{c}0.84- \\
0.91\end{array}$ & $\begin{array}{c}0.52- \\
0.59\end{array}$ & $\begin{array}{c}0.59- \\
0.70\end{array}$ & $\begin{array}{c}0.56- \\
0.68\end{array}$ & $\begin{array}{c}0.42- \\
0.52\end{array}$ & $\begin{array}{c}0.71- \\
0.81\end{array}$ & $\begin{array}{c}0.79- \\
0.85\end{array}$ & $\begin{array}{c}0.84- \\
0.90\end{array}$ \\
\hline & $p$ value $^{\mathrm{a}}$ & 0.025 & & & & & 0.006 & & & & & 0.000 & & & & & & \\
\hline
\end{tabular}

aThe $p$ values displayed in the "Pre" columns are a comparison of mean scores between intervention and control districts at baseline. These were calculated using an unpaired $t$ test. The other $p$ values, which are displayed under the intervention/control columns, are a comparison of mean differences in the pre-post scores for intervention versus control groups. $p$ values for (Pre-Int vs. Pre-Con vs. Post-Int vs. Post-Con) for Kenya, Jamaica and Uganda were calculated using an online $t$ test tool; $p$ values for South Africa were calculated using an unpaired $t$ test 
Table 8 Mean scores and occurrences for the two stigma sub-scales. For Jamaica, Kenya and Uganda, the following within-country comparisons were calculated: pre-intervention versus pre-control versus post-intervention versus post-control. For South Africa, a pre versus post comparison was calculated

\begin{tabular}{|c|c|c|c|c|c|c|c|c|c|c|c|c|c|c|c|c|c|c|c|}
\hline & & \multicolumn{5}{|c|}{ Jamaica } & \multicolumn{5}{|c|}{ Kenya } & \multicolumn{5}{|c|}{ Uganda } & \multicolumn{3}{|c|}{ South Africa } \\
\hline & & \multicolumn{2}{|c|}{ Intervention } & \multicolumn{2}{|c|}{ Control } & \multirow{2}{*}{$\begin{array}{l}\text { Int. vs. } \\
\text { con } p \text { value }\end{array}$} & \multicolumn{2}{|c|}{ Intervention } & \multicolumn{2}{|c|}{ Control } & \multirow{2}{*}{$\begin{array}{l}\text { Int. vs. } \\
\text { con } p \text { value }\end{array}$} & \multicolumn{2}{|c|}{ Intervention } & \multicolumn{2}{|c|}{ Control } & \multirow{2}{*}{$\begin{array}{l}\text { Int. vs. } \\
\text { con } p \text { value }\end{array}$} & \multicolumn{2}{|c|}{ Intervention } & \multirow{2}{*}{$\begin{array}{c}\text { Pre vs. } \\
\text { post } p \text { value }\end{array}$} \\
\hline & & Pre & Post & Pre & Post & & Pre & Post & Pre & Post & & Pre & Post & Pre & Post & & Pre & Post & \\
\hline Total \# of participants & & 121 & 93 & 95 & 104 & & 100 & 161 & 117 & 115 & & 135 & 103 & 141 & 117 & & 157 & 120 & \\
\hline \multicolumn{20}{|c|}{ Nurses stigmatising patients } \\
\hline Mean score $(S D)^{a}$ & & $\begin{array}{l}0.293 \\
(0.40)\end{array}$ & $\begin{array}{l}0.180 \\
(0.46)\end{array}$ & $\begin{array}{l}0.220 \\
(0.43)\end{array}$ & $\begin{array}{l}0.163 \\
(0.40)\end{array}$ & 0.570 & $\begin{array}{l}0.271 \\
(0.35)\end{array}$ & $\begin{array}{l}0.199 \\
(0.35)\end{array}$ & $\begin{array}{l}0.399 \\
(0.49)\end{array}$ & $\begin{array}{l}0.235 \\
(0.34)\end{array}$ & 0.201 & $\begin{array}{l}0.242 \\
(0.41)\end{array}$ & $\begin{array}{l}0.175 \\
(0.36)\end{array}$ & $\begin{array}{l}0.438 \\
(0.68)\end{array}$ & $\begin{array}{l}0.224 \\
(0.34)\end{array}$ & 0.089 & $\begin{array}{l}0.202 \\
(0.40)\end{array}$ & $\begin{array}{l}0.145 \\
(0.24)\end{array}$ & 0.003 \\
\hline \multirow[t]{3}{*}{$\begin{array}{l}\text { Count of instances } \\
n(\%)^{b}\end{array}$} & Never & $\begin{array}{c}41 \\
(33.9)\end{array}$ & $\begin{array}{c}58 \\
(62.4)\end{array}$ & $\begin{array}{c}52 \\
(54.7)\end{array}$ & $\begin{array}{c}67 \\
(64.4)\end{array}$ & 0.002 & $\begin{array}{c}35 \\
(35.0)\end{array}$ & $\begin{array}{c}83 \\
(51.6)\end{array}$ & $\begin{array}{c}40 \\
(34.2)\end{array}$ & $\begin{array}{c}55 \\
(47.8)\end{array}$ & 0.006 & $\begin{array}{c}64 \\
(47.4)\end{array}$ & $\begin{array}{c}58 \\
(56.3)\end{array}$ & $\begin{array}{c}66 \\
(46.8)\end{array}$ & $\begin{array}{c}59 \\
(50.4)\end{array}$ & 0.279 & $\begin{array}{c}91 \\
(58.0)\end{array}$ & $\begin{array}{c}59 \\
(49.2)\end{array}$ & 0.182 \\
\hline & $\begin{array}{l}\text { One or } \\
\text { more }\end{array}$ & $\begin{array}{c}60 \\
(49.6)\end{array}$ & $\begin{array}{c}32 \\
(34.4)\end{array}$ & $\begin{array}{c}32 \\
(33.7)\end{array}$ & $\begin{array}{c}28 \\
(26.9)\end{array}$ & & $\begin{array}{c}58 \\
(58.0)\end{array}$ & $\begin{array}{c}75 \\
(46.6)\end{array}$ & $\begin{array}{c}69 \\
(59.0)\end{array}$ & $\begin{array}{c}59 \\
(51.3)\end{array}$ & & $\begin{array}{c}70 \\
(51.9)\end{array}$ & $\begin{array}{c}44 \\
(42.7)\end{array}$ & $\begin{array}{c}70 \\
(49.6)\end{array}$ & $\begin{array}{c}58 \\
(49.6)\end{array}$ & & $\begin{array}{c}62 \\
(39.5)\end{array}$ & $\begin{array}{c}56 \\
(46.7)\end{array}$ & \\
\hline & Missing & $\begin{array}{c}20 \\
(16.5)\end{array}$ & $\begin{array}{c}3 \\
(3.2)\end{array}$ & $\begin{array}{c}11 \\
(1.6)\end{array}$ & $\begin{array}{c}9 \\
(8.7)\end{array}$ & & $\begin{array}{c}7 \\
(7.0)\end{array}$ & $\begin{array}{c}3 \\
(1.9)\end{array}$ & $\begin{array}{c}8 \\
(6.8)\end{array}$ & $\begin{array}{c}1 \\
(0.9)\end{array}$ & & $\begin{array}{c}1 \\
(0.7)\end{array}$ & $\begin{array}{c}1 \\
(1.0)\end{array}$ & $\begin{array}{c}5 \\
(3.5)\end{array}$ & $\begin{array}{c}0 \\
(0)\end{array}$ & & $\begin{array}{c}4 \\
(2.5)\end{array}$ & $\begin{array}{c}5 \\
(4.2)\end{array}$ & \\
\hline \multicolumn{20}{|c|}{ Nurses being stigmatised } \\
\hline Mean score (SD) ${ }^{a}$ & & $\begin{array}{l}0.195 \\
(0.32)\end{array}$ & $\begin{array}{l}0.151 \\
(0.36)\end{array}$ & $\begin{array}{l}0.113 \\
(0.26)\end{array}$ & $\begin{array}{l}0.138 \\
(0.30)\end{array}$ & 0.267 & $\begin{array}{l}0.599 \\
(0.57)\end{array}$ & $\begin{array}{l}0.567 \\
(0.68)\end{array}$ & $\begin{array}{l}0.713 \\
(0.65)\end{array}$ & $\begin{array}{l}0.648 \\
(0.70)\end{array}$ & 0.737 & $\begin{array}{l}0.841 \\
(0.65)\end{array}$ & $\begin{array}{l}0.653 \\
(0.60)\end{array}$ & $\begin{array}{l}1.331 \\
(0.76)\end{array}$ & $\begin{array}{c}0.750 \\
(0.642)\end{array}$ & 0.002 & $\begin{array}{l}0.673 \\
(0.80)\end{array}$ & $\begin{array}{l}0.565 \\
(0.76)\end{array}$ & 0.502 \\
\hline \multirow[t]{3}{*}{$\begin{array}{l}\text { Count of instances } \\
n(\%)^{b}\end{array}$} & Never & $\begin{array}{c}64 \\
(52.9)\end{array}$ & $\begin{array}{c}61 \\
(65.6)\end{array}$ & $\begin{array}{c}60 \\
(63.2)\end{array}$ & $\begin{array}{c}68 \\
(65.4)\end{array}$ & 0.148 & $\begin{array}{c}23 \\
(23.0)\end{array}$ & $\begin{array}{c}60 \\
(37.3)\end{array}$ & $\begin{array}{c}18 \\
(15.4)\end{array}$ & $\begin{array}{c}31 \\
(27.0)\end{array}$ & 0.004 & $\begin{array}{c}15 \\
(11.1)\end{array}$ & $\begin{array}{c}18 \\
(17.5)\end{array}$ & $\begin{array}{c}9 \\
(6.4)\end{array}$ & $\begin{array}{c}18 \\
(15.4)\end{array}$ & 0.014 & $\begin{array}{c}48 \\
(30.6)\end{array}$ & $\begin{array}{c}45 \\
(37.5)\end{array}$ & 0.192 \\
\hline & $\begin{array}{l}\text { One or } \\
\text { more }\end{array}$ & $\begin{array}{c}52 \\
(43.0)\end{array}$ & $\begin{array}{c}28 \\
(30.1)\end{array}$ & $\begin{array}{c}30 \\
(31.6)\end{array}$ & $\begin{array}{c}32 \\
(30.8)\end{array}$ & & $\begin{array}{c}73 \\
(73.0)\end{array}$ & $\begin{array}{c}99 \\
(61.5)\end{array}$ & $\begin{array}{c}92 \\
(78.6)\end{array}$ & $\begin{array}{c}84 \\
(73.0)\end{array}$ & & $\begin{array}{l}118 \\
(87.4)\end{array}$ & $\begin{array}{c}83 \\
(80.6)\end{array}$ & $\begin{array}{l}127 \\
(90.1)\end{array}$ & $\begin{array}{c}98 \\
(83.8)\end{array}$ & & $\begin{array}{l}106 \\
(67.5)\end{array}$ & $\begin{array}{c}71 \\
(59.2)\end{array}$ & \\
\hline & Missing & $\begin{array}{c}5 \\
(4.1)\end{array}$ & $\begin{array}{c}4 \\
(4.3)\end{array}$ & $\begin{array}{c}5 \\
(5.3)\end{array}$ & $\begin{array}{c}4 \\
(3.8)\end{array}$ & & $\begin{array}{c}4 \\
(4.0)\end{array}$ & $\begin{array}{c}2 \\
(1.2)\end{array}$ & $\begin{array}{c}7 \\
(6.0)\end{array}$ & $\begin{array}{c}0 \\
(0)\end{array}$ & & $\begin{array}{c}2 \\
(1.5)\end{array}$ & $\begin{array}{c}2 \\
(1.9)\end{array}$ & $\begin{array}{c}5 \\
(3.5)\end{array}$ & $\begin{array}{c}1 \\
(0.9)\end{array}$ & & $\begin{array}{c}3 \\
(1.9)\end{array}$ & $\begin{array}{c}4 \\
(3.3)\end{array}$ & \\
\hline
\end{tabular}

a Data used to calculate mean scores were collected via a Likert scale. Significance figures for mean scores were calculated as intervention significance versus control significance using an unpaired $t$ test. A pre versus post was used for South Africa due to no control group. Missing data were excluded

${ }^{\mathrm{b}}$ Data used to calculate the count of instances was collected on a nominal scare. Significance figures for count of instances calculated using a Mantel Haenszel chi-square for Kenya, Jamaica and Uganda; a Pearson

chi-square was used for South Africa. Missing data were excluded from calculations 
group. Overall, there was a downward trend in reports of nurses stigmatising patients in both intervention and control groups in Uganda and Kenya and in intervention groups in South Africa and Jamaica.

\section{Multivariate analysis}

There were 24 Jamaican institutions and 24 Kenyan institutions with data for both periods. The intervention effect was not statistically significant for any of the measures. Uganda was not included in this analysis due to the large amount of missing data at follow-up resulting from an administrative error, specifically, data not being collected from provincial/district hospitals (level 4). South Africa did not have a control group due to budgetary constraints and was therefore also excluded from this analysis.

\section{Process evaluation}

\section{Hub sustainability and turnover rates}

Twelve leadership hubs were set up in intervention districts across four countries. Eleven of 12 hubs remained active through to the end of the project, an average span of 3.8 years (one hub in South Africa became inactive before the project ended, after 2.8 years). The average turnover rate for hub members across all countries was $10.1 \%$. In the last 18 months, Kenya and Jamaica experienced the highest turnover rates. Primary reasons for turnover were a job transfer followed by being too busy or losing interest. The proportion of hub members reported as active in the final year of the programme ranged from 42.2 to $88.2 \%$. The proportion of hub members at follow-up who had been members since baseline ranged from $65.0 \%$ (Uganda) to $81.3 \%$ (Jamaica).

\section{Hub training}

Training progressed at different rates across countries with some locally driven variations in the sequence and selection of workshop topics, as described earlier. Not all hub members participated in all training workshops, primarily due to turnover. Each workshop was presented once, so members who were unavailable on the workshop day or who joined the hub at a later date missed that formal training session. During their second year of operation, all hubs developed district-focused health action plans targeting gaps identified in the baseline findings. They were encouraged to develop plans that included all institutions in the district, not just those that had been sampled for data collection. However, some hubs decided to focus their action on a particular tier of health facilities within their district (e.g. health centres). Hub members sometimes requested additional analyses from the research team to inform their action plans. These plans focused on issues including improving infection control; providing support activities for HIV-positive nurses; sensitising nurses to HIVrelated stigma; and increasing nurses' awareness of existing HIV workplace policies. Some plans included activities aimed at health issues other than HIV. Despite a common template that was used to guide hubs in developing plans, we observed unevenness in the specificity and level of activity proposed across action plans.

In the final year, 11 hubs completed a total of nine evaluation projects, all with a quality assurance focus (see Table 9). Hubs worked either singly or with other hubs in their country as they completed data collection, analysis and report-writing. The dissemination of findings from these projects took place in the last few months of the programme and in some cases continued after the programme ended. The proportion of intervention institutions that participated in the evaluation projects ranged from $35.3 \%$ (Jamaica) to $88.2 \%$ (Kenya).

By the end of the programme, leadership hub members in each country reported statistically significant improvements in their self-rated capacity to identify and act on gaps in clinical care and health system issues for each of the seven capacity dimensions assessed (see Table 10). Pre-post change scores ranged from 3.59 to 4.59 (on a 10-point scale) for the eight hubs included in this analysis. The largest change score was reported for the competency "initiating and undertaking an evaluation project". Data from two hubs were excluded from significance testing, as only aggregated data, rather than individual data, were provided by the RA. Competency scores from these two hubs showed the same pattern as that for the other hubs. Two other hubs were excluded; one in South Africa that was inactive and one in Uganda, whose members did not respond.

\section{Discussion}

We were able to set up, train and sustain leadership hubs in all countries over the 4-year project. However, limited changes in outcomes were observed in the study districts. We consider reasons for these overall findings and differences across countries, in the sections below.

\section{Baseline comparisons}

At baseline, our study findings showed that all study countries had some significant gaps in evidenceinformed HIV care, quality assurance initiatives and workplace policies. Family care, referrals and information exchange between health care settings were the most common gaps reported in all countries. It is not surprising that in busy and understaffed clinics and inpatient units, family-related issues get less attention. Involving family members in patient care is compounded by confidentiality issues related to HIV 
Table 9 Leadership hub evaluation projects

\begin{tabular}{|c|c|c|c|c|c|}
\hline Country & Leadership hub & Amount of grant (CAD) & Timeline & Project & Main findings and conclusions \\
\hline \multirow[t]{3}{*}{ Jamaica } & St. Thomas Hub & $\$ 847$ & May 2011-November 2011 & $\begin{array}{l}\text { Observation of infection control procedures } \\
\text { and interviews with staff to assess the } \\
\text { implementation process of Jamaica's } \\
\text { National Infection Control Policy in parish } \\
\text { health centres }\end{array}$ & $\begin{array}{l}\text { Infection control committees were vibrant and active; } \\
\text { infection control nurses deliberately assigned; } \\
\text { inadequate supplies to maintain policy standards; } \\
\text { insufficient allocation of coordinators; lack of } \\
\text { coordinated approach to training }\end{array}$ \\
\hline & St. Catherine Hub & $\$ 866$ & May 2011-February 2012 & $\begin{array}{l}\text { Analysis of hospital records and personnel } \\
\text { training to assess the implementation of } \\
\text { the voluntary counselling and testing (VCT) } \\
\text { component of the Jamaican National } \\
\text { HIV/AIDS policy in a parish hospital } \\
\text { maternity unit }\end{array}$ & $\begin{array}{l}\text { Extensive gaps in implementation and monitoring of } \\
\text { VCT policy; no inclusion of VCT in orientation of new } \\
\text { staff; low levels of VCT training; no committee to } \\
\text { ensure VCT implementation }\end{array}$ \\
\hline & $\begin{array}{l}\text { Kingston and St. } \\
\text { Andrew Hub }\end{array}$ & $\$ 993$ & May 2011-November 2011 & $\begin{array}{l}\text { Analysis of cases of occupational exposure } \\
\text { to HIV (collected through required reporting } \\
\text { and hospital injury records) to assess the } \\
\text { adherence to post-exposure prophylaxis } \\
\text { protocol in parish hospitals }\end{array}$ & $\begin{array}{l}\text { Protocols for occupational injuries followed in some } \\
\text { cases but not all; administration of post-exposure } \\
\text { prophylaxis medication followed more closely than } \\
\text { administrative aspects }\end{array}$ \\
\hline
\end{tabular}

Kenya Suba Hub $\quad \$ 834 \quad$ July 2011-March 2012

Surveys and interviews with hospital staff and clients to assess the impact of Kenya's Service Charter on Health Sector Service Provision within district hospitals

Staff are knowledgeable and are partially

implementing the service charter; there are a number of challenges preventing full implementation: human resources, finances, equipment and supplies; client satisfaction is satisfactory (60 \%)

Nyando Hub and \$1490 July 2011-March 2012

Structured questionnaires (with frontline nurses and nurse managers), and semistructured exit interviews (with clients) to assess the implementation of Kenya's National Reproductive Health Policy in Promotion of Safe Motherhood within country health facilities

Uganda Kampala Hub $\quad \$ 773 \quad$ May 2011-January 2012

Key informant interviews and focus group discussions to determine effective dissemination strategies to involve nurses dissemination strategies to involve nurses
and midwives in HIV workplace policies in and midwives in HIV
district health centres

Jinja Hub

November 2011-February 2012

Structured interviews with nurses for the identification of nurse-designed best practices for addressing HIV stigma among nurses in district health centres

Questionnaires and focus group discussions with nurses to assess health workers' knowledge, attitudes and practices towards implementation of universal safety precautions (USP) policy in district health HIV/AIDS components of the reproductive health policy are being implemented, with some exceptions; client satisfaction was above average, but there was room for improvement in some areas

Most nurses and midwives are not well conversant with HIV workplace policies; health facilities that have policies do not have them in written documents: there is a strong need to improve dissemination strategies of HIV workplace policies to nurses and midwives

Top-down efforts to reduce stigma have failed to yield significant results; leaders at various levels need to be involved in stigma reduction

High (93\%) knowledge of USP policy, but low (10 \%) use of guidelines among nurses; resources needed for implementation of policies are often lacking; need for both dissemination of policy guidelines and supplies facilities 
Table 9 Leadership hub evaluation projects (Continued)

\begin{tabular}{llll}
\hline South Africa & $\begin{array}{l}\text { Ngaka Modiri } \\
\text { Molema Hub and } \\
\text { Kenneth Kaunda } \\
\text { Hub }\end{array}$ & June 2011-February 2012 & $\begin{array}{l}\text { Literature review and concept analysis on } \\
\text { anti-retroviral therapy (ART) adherence and } \\
\text { follow-up to develop a checklist tool for } \\
\text { in institutions, and policies often not implemented, } \\
\text { well-known, or used; no policy enforcement at the } \\
\text { institutional level; current policies focus on accessibility } \\
\text { and management of medications only }\end{array}$ \\
\end{tabular}

Leadership hub evaluation projects were funded by the study ("Strengthening Nurses' Capacity in HIV Policy Development in Sub-Saharan Africa and the Caribbean"), which itself was funded by the Global Health Research Initiative (GHRI), a collaborative research funding partnership of the Canadian Institutes of Health Research, the Canadian International Development Agency, Health Canada, the International Development Research Centre, and the Public Health Agency of Canada [grant number 103460-042] 
Table 10 Active leadership hub members' self-assessed changes in capacity

\begin{tabular}{|c|c|c|c|c|c|c|c|c|c|c|c|c|c|}
\hline \multirow[t]{2}{*}{ Capacity dimension } & \multicolumn{2}{|c|}{ Jamaica ( $n=11$, three hubs) } & \multicolumn{2}{|c|}{ Kenya $\left(n=10\right.$, two hubs $\left.{ }^{a}\right)$} & \multicolumn{2}{|c|}{ Uganda $\left(n=4\right.$, one hub $\left.{ }^{a}\right)$} & \multicolumn{2}{|c|}{ South Africa ( $n=9$, two hubs) } & \multicolumn{5}{|c|}{ All countries ( $n=34$, eight hubs) } \\
\hline & $\begin{array}{l}\text { Pre } \\
\mu(\mathrm{SD})\end{array}$ & $\begin{array}{l}\text { Post } \\
\mu(\mathrm{SD})\end{array}$ & $\begin{array}{l}\text { Pre } \\
\mu(\mathrm{SD})\end{array}$ & $\begin{array}{l}\text { Post } \\
\mu(\mathrm{SD})\end{array}$ & $\begin{array}{l}\text { Pre } \\
\mu(\mathrm{SD})\end{array}$ & $\begin{array}{l}\text { Post } \\
\mu(\mathrm{SD})\end{array}$ & $\begin{array}{l}\text { Pre } \\
\mu(\text { SD) }\end{array}$ & $\begin{array}{l}\text { Post } \\
\mu(\mathrm{SD})\end{array}$ & $\begin{array}{l}\text { Pre } \\
\mu(\mathrm{SD})\end{array}$ & $\begin{array}{l}\text { Post } \\
\mu(\mathrm{SD})\end{array}$ & $t$ & Df & $p$ value $^{b}$ \\
\hline $\begin{array}{l}1 \text { Appraising existing evidence and } \\
\text { identifying gaps }\end{array}$ & $\begin{array}{c}3.45 \\
(1.72)\end{array}$ & $\begin{array}{c}8.00 \\
(0.60)\end{array}$ & $\begin{array}{l}4.10 \\
(0.94)\end{array}$ & $\begin{array}{c}7.20 \\
(0.98)\end{array}$ & $\begin{array}{l}2.50 \\
(1.12)\end{array}$ & $\begin{array}{l}7.50 \\
(2.18)\end{array}$ & $\begin{array}{c}3.56 \\
(1.34)\end{array}$ & $\begin{array}{c}7.22 \\
(1.40)\end{array}$ & $\begin{array}{c}3.56 \\
(1.44)\end{array}$ & $\begin{array}{l}7.50 \\
(1.27)\end{array}$ & 20.40 & 33 & $<0.00001$ \\
\hline $\begin{array}{l}2 \text { Initiating and undertaking an } \\
\text { evaluation project }\end{array}$ & $\begin{array}{l}3.36 \\
(2.14)\end{array}$ & $\begin{array}{l}7.82 \\
(0.72)\end{array}$ & $\begin{array}{l}3.30 \\
(1.27)\end{array}$ & $\begin{array}{c}8.10 \\
(0.83)\end{array}$ & $\begin{array}{l}2.00 \\
(0.71)\end{array}$ & $\begin{array}{l}7.00 \\
(1.87)\end{array}$ & $\begin{array}{l}2.89 \\
(1.29)\end{array}$ & $\begin{array}{l}7.22 \\
(1.69)\end{array}$ & $\begin{array}{c}3.06 \\
(1.63)\end{array}$ & $\begin{array}{l}7.65 \\
(1.30)\end{array}$ & 23.07 & 33 & $<0.00001$ \\
\hline 3 Ability to disseminate findings & $\begin{array}{l}4.55 \\
(2.57)\end{array}$ & $\begin{array}{l}8.18 \\
(0.94)\end{array}$ & $\begin{array}{c}4.80 \\
(1.25)\end{array}$ & $\begin{array}{l}7.90 \\
(1.04)\end{array}$ & $\begin{array}{l}3.25 \\
(1.48)\end{array}$ & $\begin{array}{l}7.25 \\
(1.48)\end{array}$ & $\begin{array}{c}4.44 \\
(1.64)\end{array}$ & $\begin{array}{l}8.33 \\
(1.56)\end{array}$ & $\begin{array}{c}4.44 \\
(1.94)\end{array}$ & $\begin{array}{l}8.03 \\
(1.27)\end{array}$ & 12.66 & 33 & $<0.00001$ \\
\hline 4 Valuing policy relevance and access & $\begin{array}{l}3.91 \\
(2.35)\end{array}$ & $\begin{array}{l}8.36 \\
(1.43)\end{array}$ & $\begin{array}{c}4.00 \\
(1.41)\end{array}$ & $\begin{array}{l}7.70 \\
(1.19)\end{array}$ & $\begin{array}{l}2.25 \\
(1.09)\end{array}$ & $\begin{array}{l}5.25 \\
(1.79)\end{array}$ & $\begin{array}{l}3.22 \\
(1.13)\end{array}$ & $\begin{array}{l}8.11 \\
(1.66)\end{array}$ & $\begin{array}{l}3.56 \\
(1.79)\end{array}$ & $\begin{array}{l}7.74 \\
(1.75)\end{array}$ & 14.31 & 33 & $<0.00001$ \\
\hline $\begin{array}{l}5 \text { Confidence to communicate to } \\
\text { decision-makers }\end{array}$ & $\begin{array}{l}4.36 \\
(2.46)\end{array}$ & $\begin{array}{l}8.55 \\
(0.89)\end{array}$ & $\begin{array}{c}4.90 \\
(1.30)\end{array}$ & $\begin{array}{c}8.50 \\
(1.28)\end{array}$ & $\begin{array}{c}3.25 \\
(1.64)\end{array}$ & $\begin{array}{l}7.00 \\
(1.41)\end{array}$ & $\begin{array}{c}3.33 \\
(1.70)\end{array}$ & $\begin{array}{l}8.33 \\
(1.76)\end{array}$ & $\begin{array}{c}4.12 \\
(2.00)\end{array}$ & $\begin{array}{c}8.29 \\
(1.43)\end{array}$ & 14.78 & 33 & $<0.00001$ \\
\hline $\begin{array}{l}6 \text { Valuing contributions from people } \\
\text { in different roles and levels }\end{array}$ & $\begin{array}{c}5.00 \\
(2.41)\end{array}$ & $\begin{array}{l}8.91 \\
(0.79)\end{array}$ & $\begin{array}{l}6.10 \\
(1.92)\end{array}$ & $\begin{array}{c}9.00 \\
(1.26)\end{array}$ & $\begin{array}{l}3.25 \\
(1.48)\end{array}$ & $\begin{array}{l}8.00 \\
(1.22)\end{array}$ & $\begin{array}{l}3.67 \\
(1.56)\end{array}$ & $\begin{array}{c}8.00 \\
(1.33)\end{array}$ & $\begin{array}{c}4.76 \\
(2.24)\end{array}$ & $\begin{array}{l}8.59 \\
(1.24)\end{array}$ & 12.03 & 33 & $<0.00001$ \\
\hline $\begin{array}{l}7 \text { Leadership and team skills to } \\
\text { improve the health system }\end{array}$ & $\begin{array}{c}4.64 \\
(2.19)\end{array}$ & $\begin{array}{l}8.64 \\
(1.07)\end{array}$ & $\begin{array}{l}6.20 \\
(1.33)\end{array}$ & $\begin{array}{c}9.10 \\
(0.70)\end{array}$ & $\begin{array}{l}4.00 \\
(1.73)\end{array}$ & $\begin{array}{l}8.75 \\
(0.83)\end{array}$ & $\begin{array}{l}4.56 \\
(0.96)\end{array}$ & $\begin{array}{l}8.89 \\
(1.20)\end{array}$ & $\begin{array}{l}5.00 \\
(1.81)\end{array}$ & $\begin{array}{l}8.85 \\
(1.00)\end{array}$ & 17.10 & 33 & $<0.00001$ \\
\hline
\end{tabular}

${ }^{\mathrm{a}}$ Data from two hubs (one in Kenya, one in Uganda) were excluded from significance testing, as only aggregated data, rather than individual data were provided by the RA. Competency scores from these two hubs showed the same pattern as that for the other hubs

${ }^{b}$ A paired $t$ test was used to determine the significance of pre versus post differences 
disclosure to patients' partners, and concerns about stigmatisation $[9,88]$. Nurses may have assumed that family dimensions of HIV care were being addressed through voluntary counselling and testing programmes, or by other members of the health care team. There are also country-specific reasons for these findings. For instance, nurses working in Jamaica's health centres have little interaction with HIV patients after they are diagnosed, as follow-up care is provided by doctors and adherence counsellors.

There were gaps in workplace policies and quality assurance programmes as well. A number of these mirrored the gaps observed for clinical care. There was also more variability across countries with respect to these policies and programmes. These reflect, in part, considerable differences in the HIV policy context [89] and socio-political influences such as legislation and norms regarding homosexuality.

\section{Pre-post changes in clinical practices, workplace policies and quality assurance}

Despite significant improvements in the self-rated capacity of hub members in all countries, there were only small, although statistically significant, pre-post improvements in workplace policies and quality assurance in Jamaica (pre-post, intervention versus control group comparisons) and modest improvements in clinical practices, workplace policies and quality assurance in South Africa (pre-post comparisons). There were small but statistically significant improvements in pre-post scores for nurses stigmatising patients in Jamaica, Kenya and South Africa and for nurses being stigmatised in Kenya, but no statistical adjustment was made for either multiple testing or clustering effects. Multivariate analysis models for Jamaica and Kenya that adjusted for differences across WHO institution levels yielded non-significant results. In Uganda, improvements in the control group for both stigma and quality assurance exceeded those in the intervention groups. The biggest pre-post changes in the intervention groups were seen in South Africa. However, there was no control group in this country.

\section{Co-interventions}

The improvement in stigma scores across all countries (nurses' reports of both stigmatising and being stigmatised), in both intervention and control groups, suggests a trend towards less HIV-related stigma. Stigma reduction has been a priority for many HIV programmes. In Jamaica, for example, an island-wide stigma reduction campaign was introduced during the study period by the Pan Caribbean Partnership against AIDS [90]. In Kenya, Uganda and South Africa, numerous professional development training programmes targeting service delivery issues including voluntary testing and counselling, stigma, access to HIV care and integrated models of care were offered by Ministries, development aid and non-governmental organisations during the study period $[4,12,19,20,31,34,42,45,47]$. Changes in national level policies on access to HIV care were also evident during the study period with some of the biggest change taking place in South Africa [83]. We did not systematically track these co-interventions. It seems likely that these other interventions may have led to some of the improvements observed, particularly in South Africa.

\section{Hub intervention}

Since trust among partners is a critical prerequisite for effective PAR [91], this may have influenced how quickly the intervention took hold and what activities were prioritised by hubs. Pre-existing relationships between the institutions where research project leads for the hub intervention were employed and the study districts varied substantially.

Our process evaluation of the hubs highlights some strengths of the intervention. The hubs comprised a corps of nurses and health system stakeholders committed to improving HIV prevention and care-related services and policies. Hub members in all districts reported capacity improvements. They gained introductory skills in research, evaluation and influencing workplace policies. However, our experience working with hub members to develop and refine their evaluation projects suggests that in some cases, their self-reported confidence in using these skills may have outstripped their actual ability to use them independently.

A core group of hub members remained engaged throughout the 4-year project period and 11 of the 12 hubs remained active at the end of the programme; $71.7 \%$ of those who were still in the hub at the end of the study had been involved in the hub since the outset. Country directors were able to oversee the recruitment of hub members and replace those who left early, suggesting that the opportunity to participate as a leadership hub member was valued and hubs as an entity were sustained. The substantial proportion of unremunerated time hub members spent attending training and meetings, and developing and implementing both their action plans and evaluation projects also indicates that this opportunity was viewed positively.

Overall, despite these apparent strengths of the leadership hub intervention, district-wide improvements in practice and policy outcomes were not seen. There are two major plausible explanations for these results: the strength and intensity of the intervention was inadequate, and/or outcome measures were not sensitive to intervention effects. 


\section{Intervention strength and intensity}

Several factors diluted the potential strength of the hub intervention. Hub activities were significantly disrupted in areas where there were more acute shortages of health care providers and challenging socio-political influences. In both Kenya and Uganda, for example, major reorganisations of their health system led to the redeployment of many health workers, including some hub members. This led to some loss of momentum among hubs as health workers became demoralised as a result of these larger system changes, particularly in Uganda and Kenya.

There were delays in getting baseline data findings to the hubs for their input and feedback, and this may have initially discouraged members. Because we piggy-backed capacity building of country RAs with analysis, results were shared more slowly than initially planned and hubs were sometimes kept waiting for study findings [77]. This may have contributed to some of the unevenness we observed in the content of the action plans across countries and the initial inclusion of some non-HIVrelated activities in some of the earlier plans.

While we attempted to ensure links with the formal system by establishing national advisory committees within three countries, requiring that hub members were employed in the study districts and asking hub members to seek their employers' permission to participate in hub activities, the hubs as an entity were not a recognised formal structure of the health system. Research highlights the importance of integrated governance structures, formal decision-making authority and accountability chains within the system as dimensions of committees that can stimulate wide-scale system change [92-94]. However, these dimensions were missing from our hubs.

Hub members found their work priorities and responsibilities competing with hub time commitments. Furthermore, hub members were not paid by our programme, an approach that was different from the more common practice of non-governmental organisations in the study countries, which normally pay a training allowance or replacement wages to the employee's institution. Coupled with the fact that leadership hubs were not a formal part of the health care system, this made it difficult for hub members to negotiate release time with their employers. This was even more challenging when districts were dealing with urgent matters such as disease outbreaks (e.g., cholera, H1N1), local natural disasters, national health campaigns, periods of civil unrest and labour disruptions. All of these put extra demands on the scarce human resources available.

Hub members set priorities for two core activities-preparing an action plan and developing an evaluation project. The former posed challenges because the hubs were informal structures, without any direct accountability within the system. This left no formal mechanism for approving their action plans and led to questions about what they were authorised to do. In contrast, the development of evaluation plans provided a turning point for the hubs. Members had to seek administrative approval of participating institutions where they decided to undertake the work. This gave a formal accountability mechanism to provide feedback and recommendations for action. However, in most instances, evaluation projects were completed just a few months before follow-up data for the study were gathered and involved a subset of sampled organisations in the intervention districts. In South Africa, the two active hubs carried out a joint project which involved a literature review and subsequent development of an assessment instrument. Actual implementation of this assessment instrument (to improve continuity of care for HIV patients) was planned for after the project period. Therefore, changes seen in South Africa are not likely due to their evaluation project.

\section{Sensitivity of outcome measures}

HIV care outcome measures for the study were chosen in advance of establishing the hubs. Therefore, they did not reflect the specific focus of the hub action plans and evaluation projects. Since the interventions were hubdriven, similar to a "community-driven" intervention [95], this put our PAR approach at odds with our quasiexperimental design and outcome measures. Yet, the quantitative baseline measures were a critical input into the PAR process. Baseline data comprised an essential set of local and evidence-informed HIV health care indicators that were specific to nursing practice, which hub members considered as they developed their action plans and decided on a focus for their evaluation projects.

Action plans developed by hubs were diffuse. Although evaluation projects were focused, they did not nearly cover the breadth of outcomes assessed. We did not impose a requirement for hub activities to be undertaken in the randomly sampled institutions where study data was being collected and more than half of the hub members came from health facilities or other institutions that were not part of the study sample. Furthermore, not all study institutions had hub members. Thus, we had a district-wide, health system improvement orientation to our sampling and measurement, while hubs chose a more targeted approach to their implementation of action plans and evaluation projects, which did not involve all sampled organisations. In retrospect, we set the bar extremely high in terms of expected outcomes, as hub members were neither working to create changes across 
the full spectrum of study measures nor representing or targeting all sampled study institutions.

\section{Research limitations}

There were several limitations of the research design. One of these was planned, while others emerged during the study. We did not have a control group in South Africa. This was due to budgetary constraints. A control group in this country would have helped our interpretation of the pre-post improvements we observed. Uganda experienced the biggest challenges in data collection with some notable gaps in the institutions from which data were collected during follow-up. There were several reasons for this including unanticipated changes in research assistants who had to be retrained and some other internal difficulties in that country. This further limits our interpretation of findings from Uganda and meant that we could not include that country in the multivariate analysis. Working across the four countries was a logistical challenge. We had a strong governance structure for our project which helped us operationalise the work but day-to-day communication when problems arose was difficult due to limited internet and challenging phone connections (particularly in Kenya and Uganda) at the time of the study. Our annual face-toface meetings were critical to the work of the project and both research assistants and study investigators attended these meetings. However, providing timely support for colleagues when issues arose during field work was more challenging.

\section{Intervention design challenges}

In retrospect, this project had three main intervention design challenges. First, leadership hubs did not exist within the formal decision-making and accountability structure of the health system, which would otherwise have provided oversight, support and recognition. Second, we did not give preference to data that could be rapidly and iteratively collected, such as data from district health information systems as reported in some other large-scale evaluations of HIV programmes [96]. This would have complemented data collected by our team and provided timely, ongoing feedback to hub members on progress made. Third, we did not adequately extend the membership reach of the hubs nor did we actively recruit a critical mass of hub members in larger health care institutions. Finally, neither hub members nor their home organisations received any remuneration for participation in hub activities, and we did not offer funding for activities planned as part of hub action plans. Providing some remuneration would have allowed for more rapid implementation of hub activities, although this would fail to address either the underlying constraint of limited human resources or the informal nature of the hubs.

\section{Future research}

Although our capacity measures did capture some characteristics of leadership, we did not use a comprehensive measure of leadership among hub members. Other leadership attributes such as interpersonal relationships, future vision and the ability to manage change [97] would be useful to include in future studies. We only measured self-assessed perceptions of capacity among hub members at the end of the project. Repeated measures would allow further delineation of the pathways through which leadership characteristics develop and exert change.

Synchronising hub initiatives with other programmes targeting HIV could help leverage conditions for change and would be a useful area for future inquiry. During the final phase of the study, some of this synchronisation started to take place but we did not actively catalyse these alignment opportunities.

Although we experienced a number of implementation challenges reflecting the diversity of contexts in which the study was undertaken, we think that comparative research across district and country sites remains important. It is through such comparative studies that insights can be gleaned on how interventions interact with dynamic health care systems and how interventions need to be adapted and tailored to local conditions. In this study, action plans and evaluation projects reflected local concerns and the situational analysis undertaken through the PAR process. We provide a more detailed description of how these contexts impacted on the PAR processes and the experience of leadership hub members within the study in another paper [76].

\section{Contribution to new knowledge}

This is the only study we are aware of that has attempted to link a PAR and leadership-oriented intervention to outcomes at the district health system level. The study highlights promising elements of an intervention to improve evidence-informed nursing care practices and policies by strengthening nurses' leadership and policy engagement capacity but illustrates the challenges of achieving health system impact.

\section{Limitations}

Our study had several limitations. We were unable to include control districts in South Africa due to budgetary constraints. For some indicators and especially in Kenya, baseline scores on some clinical practices and workplace policies were quite high, with limited room for improvement.

Hub members provided a self-assessment of their pre and post capacity at the end of the study. Had we 
assessed their skills at the outset of their involvement on hubs, their baseline results may have been different. We do not know if capacity gains were sustained over time.

We did not include quantitative indicators of management, leadership or governance at the level of the health care institutions, other than a human resources management rapid assessment tool [98]. Results from the latter tool, which was completed by a purposeful sample of respondents, are being written up in a separate manuscript. Some dimensions of governance were examined by leadership hubs in their evaluation projects.

\section{Conclusions}

PAR, with collaboration between nurses and decisionmakers, can bring to light gaps in the health care system and identify ways to improve clinical practice and care. Leadership hubs comprising people capable of and committed to change and provided with capacity building and mentorship can collectively identify issues and act on strategies that may improve practice and policy. It is apparent that targeted change strategies are a more realistic short-term expectation of leadership hubs than district-level health system improvements. Funding hubled evaluation projects created a necessary mechanism for hub reporting, feedback and accountability within the health care system. This type of mechanism is essential for formalised systems' change processes.

Overall, leadership hubs did not provide the necessary force for nurses to improve HIV care in their districts. If entities such as leadership hubs are to succeed, they must be integrated within district health authorities as participatory policy and practice mechanisms and become part of established formal, legal organisations (such as nursing associations or academic institutions) in order to regularise and sustain them as a means to improve health system performance.

\section{Disclosures}

In 2007, a large multidisciplinary team of researchers and decision-makers from Canada and five LMICs (Barbados, Jamaica, Kenya, Uganda and South Africa) received funding to implement a PAR programme entitled "Strengthening Nurses' Capacity for HIV Policy Development in sub-Saharan Africa and the Caribbean." One year after programme funding was received and prior to any data collection, Barbados withdrew from the programme, with the four remaining partner countries continuing [77].

\section{Endnotes}

${ }^{1}$ No further differentiation is made between nurses and midwives; the term nurse is used for the rest of the article.
2“Strengthening Nurses' Capacity in HIV Policy Development in Sub-Saharan Africa and the Caribbean".

${ }^{3}$ District refers to both districts (Kenya, Uganda, South Africa) and parishes (Jamaica).

${ }^{4}$ No control group was included in South Africa due to budgetary constraints.

${ }^{5}$ The lead project researcher in each country provided direction and day-to-day guidance for all research activities in that country.

${ }^{6}$ Level 3 corresponds to health centres; level 4 are district hospitals; and level 5 are provincial and national referral hospitals.

${ }^{7}$ To be eligible for enrolment in the study, health centres had to meet the WHO health criteria for staffing, and not just be designated as a health centres by the Ministry of Health.

\section{Additional file}

Additional file 1: Table S1. Ethics Approvals \& Institutional Letters of Permission. (DOC $34 \mathrm{~kb}$ )

\section{Abbreviations}

AIDS, acquired immune deficiency syndrome; ANOVA, analysis of variance; ART, antiretroviral therapy; CHWs, community health workers; HIV, human immunodeficiency virus; HSD, honestly significant difference; LMICs, low- and middle-income countries; PAR, participatory action research; RAs, research assistants; SD, standard deviation; WHO, World Health Organization

\section{Acknowledgements}

This research was carried out with support from the Global Health Research Initiative (GHRI), a collaborative research funding partnership of the Canadian Institutes of Health Research, the Canadian International Development Agency, Health Canada, the International Development Research Centre, and the Public Health Agency of Canada [grant number 103460-042]. The funding body played no role in the design, collection, analysis or interpretation of data, or in the writing of the manuscript for publication. Writing of the manuscript was supported through a grant for Programs of Research and Multiple Interventions in Community Health from the Canadian Institutes of Health Research [grant number 122510]. The authors gratefully acknowledge the work of the 12 leadership hubs. We acknowledge the contribution of research assistants in Canada (Katie Hoogeveen, Cody Anderson); Kenya (Edith Akunja, Irene Obago); Jamaica (Uki Atkinson); Uganda (Eric Ssegujja, Enid Mwebazza); and South Africa (Francois Watson, Rina Muller). We wish to thank study co-investigators, especially Mariam Walusimbi, Uganda Country Programme Director, and the Uganda research team. We acknowledge research collaborators and National Advisory Committee members in Kenya, Jamaica, Uganda and South Africa.

\section{Authors' contributions}

$\mathrm{NE}$ co-conceived the project, developed the study design, wrote the research and ethics protocols; co-led the training of RAs, led quantitative data analyses and interpretation, and drafted and revised the manuscript. DK contributed to proposal development, introduced a core concept of the intervention - horizontal and vertical connectivity to leverage the capacity of leadership hubs to influence policy and practice, directed all research activities in Kenya and provided input and guidance to country directors in Uganda and South Africa. EK contributed to proposal development, led RA training and directed and supervised all research activities in Jamaica. HK contributed to conceptualising the study design and managed all research activities in South Africa. JM co-conceived the original project, contributed to the study design and provided leadership on capacity development workshops for RAs, and on qualitative data collection, analysis and interpretation. JW contributed to conceptualising the study and in particular, the concept and design of leadership hubs. SR contributed to preparing the study 
protocol, co-led training of RAs and coordinated research activities among the investigators and across the four study countries. JH contributed to conceptualising the study design, and assisted with qualitative data collection, analysis and interpretation for the process evaluation of hubs. All authors critically reviewed drafts of the manuscript and approved the final version.

\section{Authors' information}

NE was the principal investigator of the study.

DK was co-principal investigator of the study and the Kenya country programme director.

EK was co-principal investigator of the study and the Jamaica country programme director.

HK was a co-investigator for the study and the South Africa country programme director.

SR was the Canadian programme manager and a co-investigator for the study.

JM, JW and JH were co-investigators of the study.

\section{Competing interests}

The authors declare that they have no competing interests.

\section{Ethics approval and consent to participate}

Ethics approval was obtained from 15 research ethics boards in Canada and all study countries (see Additional file 1: Table S1). Letters of permission were obtained from all health institutions involved in the study.

\section{Author details}

${ }^{1}$ School of Nursing, Faculty of Health Sciences, University of Ottawa, Ottawa, Canada. ${ }^{2}$ Great Lakes University of Kisumu, Kisumu, Kenya. ${ }^{3}$ School of Nursing, University of West Indies, Mona, Kingston, Jamaica. ${ }^{4}$ Rectorate, Stellenbosch University, Cape Town, South Africa. ${ }^{5}$ Faculty of Nursing, University of Alberta, Edmonton, Canada. ${ }^{6}$ Coady International Institute, St. Francis Xavier University, Antigonish, Canada. ${ }^{7}$ Faculty of Health Sciences, University of Lethbridge, Lethbridge, Canada.

\section{Received: 5 January 2016 Accepted: 25 July 2016}

\section{Published online: 03 August 2016}

\section{References}

1. Kredo T, Ford N, Adeniyi FB, Garner P. Decentralising HIV treatment in lower- and middle-income countries. Sao Paulo Med J. 2014;132:383.

2. Martin C, Masote M, Hatcher A, Black V, Venter WDF, Scorgie F. HIV testing in the critical care setting: views of patients, family members and health providers from urban South Africa. AIDS Care. 2015;27:581-6.

3. Mutemwa R, Mayhew S, Colombini M, Busza J, Kivunaga J, Ndwiga C. Experiences of health care providers with integrated HIV and reproductive health services in Kenya: a qualitative study. BMC Health Serv Res. 2013;13:18.

4. PEPFAR. Report to Congress by the U.S. Global AIDS Coordinator on Best Practices and Cost Effectiveness [Internet]. Washington, DC: Office of U.S. Global AIDS Coordinator; 2010 Aug p. 6. Available from: http://www.pepfar. gov/documents/organization/148804.pdf.

5. Tawfik L, Kinoti SN. The impact of HIV/AIDS on the health workforce in developing countries. Geneva: World Health Organization; 2006.

6. Ekstrand ML, Ramakrishna J, Bharat S, Heylen E. Prevalence and drivers of HIV stigma among health providers in urban India: implications for interventions. J Int AIDS Soc. 2013:16:18717.

7. Harrowing JN, Mill J. Moral distress among Ugandan nurses providing HIV care: a critical ethnography. Int J Nurs Stud. 2010;47:723-31.

8. IwU EN, Holzemer WL. Task shifting of HIV management from doctors to nurses in Africa: clinical outcomes and evidence on nurse self-efficacy and job satisfaction. AIDS Care. 2014;26:42-52.

9. Mill J, Harrowing J, Rae T, Richter S, Minnie K, Mbalinda S, et al. Stigma in AIDS nursing care in sub-Saharan Africa and the Caribbean. Qual Health Res. 2013;23:1066-78.

10. Munjanja OK, Kibuka S, Dovlo D. The nursing workforce in sub-Saharan Africa. Geneva: The Global Nursing Review Initiative; 2005.

11. Rosenburg N, Taliaferro D, Ercole P. HIV-related stigma among nursing students in Cameroon. J Assoc Nurses AIDS Care. 2012;23:170-6.
12. Stangl AL, Lloyd JK, Brady LM, Holland CE, Baral S. A systematic review of interventions to reduce HIV-related stigma and discrimination from 2002 to 2013: how far have we come? J Int AIDS Soc. 2013;16:18734.

13. Waluyo A, Culbert GJ, Levy J, Norr KF. Understanding HIV-related stigma among Indonesian nurses. J Assoc Nurses AIDS Care. 2015;26:69-80.

14. Nawafleh $H$, Francis $K$, Chapman Y. The impact of nursing leadership and management on the control of HIV/AIDS: an ethnographic study. Contemp Nurse. 2012;42:247-57.

15. Zuber A, McCarthy CF, Verani AR, Msidi E, Johnson C. A survey of Nurse-Initiated and -Managed Antiretroviral Therapy (NIMART) in practice, education, policy, and regulation in East, Central, and Southern Africa. J Assoc Nurses AIDS Care. 2014;25:520-31.

16. Chopra M, Daviaud E, Pattinson R, Fonn S, Lawn JE. Saving the lives of South Africa's mothers, babies, and children: can the health system deliver? Lancet. 2009:374:835-46.

17. Dohrn J, Nzama B, Murrman M. The impact of HIV scale-up on the role of nurses in South Africa: time for a new approach: JAIDS J. Acquir Immune Defic Syndr. 2009;52:S27-9

18. Sengupta S, Banks B, Jonas D, Miles MS, Smith GC. HIV interventions to reduce HIV/AIDS stigma: a systematic review. AIDS Behav. 2011;15:1075-87.

19. Mills EJ, Lester R, Thorlund K, Lorenzi M, Muldoon K, Kanters S, et al. Interventions to promote adherence to antiretroviral therapy in Africa: a network meta-analysis. Lancet HIV. 2014;1:e104-11.

20. Medley A, Bachanas P, Grillo M, Hasen N, Amanyeiwe U. Integrating prevention interventions for people living with HIV into care and treatment programs: a systematic review of the evidence. JAIDS J Acquir Immune Defic Syndr. 2015;68:S286-96.

21. Aantjes CJ, Ramerman L, Bunders JFG. A systematic review of the literature on self-management interventions and discussion of their potential relevance for people living with HIV in sub-Saharan Africa. Patient Educ Couns. 2014;95:185-200

22. Gammon J, Gould D. Universal precautions: a review of knowledge, compliance and strategies to improve practice. J Res Nurs. 2005;10:529-47.

23. Assefa Y, Van Damme W, Mariam DH, Kloos H. Toward universal access to HIV counseling and testing and antiretroviral treatment in Ethiopia: looking beyond HIV testing and ART initiation. AIDS Patient Care STDs. 2010;24:521-5.

24. Callaghan M, Ford N, Schneider $\mathrm{H}$. A systematic review of task-shifting for HIV treatment and care in Africa. Hum Resour Health. 2010;8:8.

25. Kredo T, Adeniyi FB, Bateganya M, Pienaar ED. Task shifting from doctors to non-doctors for initiation and maintenance of antiretroviral therapy. In: The Cochrane Collaboration, editor. Cochrane Database Syst. Rev. 2014.

26. Mdege ND, Chindove S, Ali S. The effectiveness and cost implications of task-shifting in the delivery of antiretroviral therapy to HIV-infected patients: a systematic review. Health Policy Plan. 2013;28:223-36.

27. Morris MB, Chapula BT, Chi BH, Mwango A, Chi HF, Mwanza J, et al. Use of task-shifting to rapidly scale-up HIV treatment services: experiences from Lusaka, Zambia. BMC Health Serv Res. 2009;9:5.

28. Penazzato M, Davies M-A, Apollo T, Negussie E, Ford N. Task shifting for the delivery of pediatric antiretroviral treatment: a systematic review. JAIDS. 2014;65:414-22.

29. Shumbusho F, van Griensven J, Lowrance D, Turate I, Weaver MA, Price J, et al. Task shifting for scale-up of HIV care: evaluation of nurse-centered antiretroviral treatment at rural health centers in Rwanda. PLoS Med. 2009:6:e1000163.

30. Lehmann U, Sanders D. Community health workers: what do we know about them? Geneva: World Health Organization; 2007.

31. Brennan A, Browne JP, Horgan M. A systematic review of health service interventions to improve linkage with or retention in HIV care. AIDS Care. 2014;26:804-12.

32. Govindasamy D, Meghij J, Negussi EK, Baggaley RC, Ford N. Interventions to improve or facilitate linkage to or retention in pre-ART (HIV) care and initiation of ART in low- and middle-income settings - a systematic review. J. Int. AIDS Soc. [Internet]. 2014 [cited 2016 Jan 4];17. Available from: http:// www.jiasociety.org/index.php/jias/article/view/19032.

33. Lindegren ML, Kennedy CE, Bain-Brickley D, Azman H, Creanga AA, Butler LM, et al. Integration of HIV/AIDS services with maternal, neonatal and child health, nutrition, and family planning services. In: The Cochrane Collaboration, editor. Cochrane Database Syst. Rev. [Internet]. Chichester, UK John Wiley \& Sons, Ltd; 2012 [cited 2016 Jan 4]. Available from: http://doi. wiley.com/10.1002/14651858.CD010119. 
34. Suthar AB, Rutherford GW, Horvath T, Doherty MC, Negussie EK. Improving antiretroviral therapy scale-up and effectiveness through service integration and decentralization. AIDS. 2014;28:S175-85.

35. Gilks CF, Crowley S, Ekpini R, Gove S, Perriens J, Souteyrand Y, et al. The WHO public-health approach to antiretroviral treatment against HIV in resource-limited settings. Lancet. 2006;368:505-10.

36. Kabore I, Bloem J, Etheredge G, Obiero W, Wanless S, Doykos P, et al. The effect of community-based support services on clinical efficacy and healthrelated quality of life in HIV/AIDS patients in resource-limited settings in sub-Saharan Africa. AIDS Patient Care STDs. 2010;24:581-94.

37. Kim JY, Farmer P, Porter ME. Redefining global health-care delivery. Lancet. 2013;382:1060-9.

38. Vasan A, Ellner A, Lawn SD, Gove S, Anatole M, Gupta N, et al. Integrated care as a means to improve primary care delivery for adults and adolescents in the developing world: a critical analysis of Integrated Management of Adolescent and Adult Illness (IMAI). BMC Med. 2014;12:6.

39. Ferguson L, Grant AD, Watson-Jones D, Kahawita T, Ong'ech JO, Ross DA. Linking women who test HIV-positive in pregnancy-related services to longterm HIV care and treatment services: a systematic review: linking HIV-positive pregnant women to treatment services. Trop Med Int Health. 2012;17:564-80.

40. Bandura A. Self-Efficacy: The Exercise of Control. New York: W.H. Freeman; 1997.

41. Lorig KR. Self-management of chronic illness: a model for the future. Generations. 1993:17:11

42. Yassi A, O'Hara LM, Lockhart K, Spiegel JM. Workplace programmes for HIV and tuberculosis: a systematic review to support development of international guidelines for the health workforce. AIDS Care. 2013;25:525-43.

43. Gimbel S, Voss J, Mercer MA, Zierler B, Gloyd S, Coutinho MJ, et al. The prevention of mother-to-child transmission of HIV cascade analysis tool: supporting health managers to improve facility-level service delivery. BMC Res Notes. 2014;7:743.

44. Doherty T, Chopra M, Nsibande D, Mngoma D. Improving the coverage of the PMTCT programme through a participatory quality improvement intervention in South Africa. BMC Public Health. 2009;9:406.

45. Mate KS, Ngubane G, Barker PM. A quality improvement model for the rapid scale-up of a program to prevent mother-to-child HIV transmission in South Africa. Int J Qual Health Care. 2013;25:373-80.

46. Sherr K, Gimbel S, Rustagi A, Nduati R, Cuembelo F, Farquhar C, et al. Systems analysis and improvement to optimize PMTCT (SAIA): a cluster randomized trial. Implement Sci. 2014;9:5908-9.

47. Marquez L, Holschneider S, Broughton E, Hiltebeitel S. Improving health care: the results and legacy of the USAID Health Care Improvement Project [Internet]. Bethesda, MD: University Research Co., LLC; 2014. Available from: https://www.usaidassist.org/sites/assist/files/improving_health_care_ resultslegacy_hci_sept2014_0.pdf.

48. Jones D, Weiss S, Chitalu N. HIV prevention in resource limited settings: a case study of challenges and opportunities for implementation. Int J Behav Med. 2014;22:384-92.

49. Koester KA, Maiorana A, Vernon K, Myers J, Rose CD, Morin S. Implementation of HIV prevention interventions with people living with HIV/AIDS in clinical settings: challenges and lessons learned. AIDS Behav. 2007;11:17-29.

50. Mwai GW, Mburu G, Torpey K, Frost P, Ford N, Seeley J. Role and outcomes of community health workers in HIV care in sub-Saharan Africa: a systematic review. J Int AIDS Soc. 2013;16:18586.

51. Leon N, Lewin S, Mathews C. Implementing a provider-initiated testing and counselling (PITC) intervention in Cape Town, South Africa: a process evaluation using the normalisation process model. Implement Sci. 2013;8:97.

52. Asuquo EF, Etowa J, John M, Ndiok A. Assessing nurses' capacity for health research and policy engagement in Nigeria. J Appl Med Sci. 2013;2:35-51.

53. Edwards N, Barker PM. The importance of context in implementation research. JAIDS. 2014;67:S157-62.

54. Harrowing J. The impact of HIV education on the lives of Ugandan nurses and nurse-midwives. Adv Nurs Sci. 2009;32:E94-E108.

55. Juma PA, Edwards N, Spitzer D. Kenyan nurses involvement in national policy development processes. Nurs Res Pract. 2014;2014:1-10.

56. Richter MS, Mill J, Muller CE, Kahwa E, Etowa J, Dawkins P, et al. Nurses' engagement in AIDS policy development. Int Nurs Rev. 2013;60:52-8.

57. Walker L, Gilson L. "We are bitter but we are satisfied": nurses as street-level bureaucrats in South Africa. Soc Sci Med. 2004;59:1251-61.

58. Evans $C$, Ndirangu E. The nursing implications of routine provider-initiated HIV testing and counselling in sub-Saharan Africa: a critical review of new policy guidance from WHO/UNAIDS. Int J Nurs Stud. 2009;46:723-31.
59. Purdy N, Lefebre N, Pogue PM, Gifford W, Patrick AW, Stewart-Pyne A. Leadership best practice guidelines: every nurse a leader. 2013 [cited 2016 May 24]; Available from: http://www.nursinglibrary.org/vhl/handle/10755/ 304173

60. Berta W, Virani T, Bajnok I, Edwards N, Rowan M. Understanding whole systems change in health care: insights into system level diffusion from nursing service delivery innovations - a multiple case study. Evid Policy J Res Debate Pract. 2014;10:313-36.

61. Ploeg J, Skelly J, Rowan M, Edwards N, Davies B, Grinspun D, et al. The role of nursing best practice champions in diffusing practice guidelines: a mixed methods study. Worldviews Evid-Based Nurs Sigma Theta Tau Int Honor Soc Nurs. 2010;7:238-51

62. Davies B, Edwards N, Ploeg J, Virani T. Insights about the process and impact of implementing nursing guidelines on delivery of care in hospitals and community settings. BMC Health Serv Res. 2008:8:29.

63. Daire J, Gilson L, Cleary S. RESYST Working Paper 4: developing leadership and management competencies in low and middle-income country health systems. A review of the literature on health leadership and management [Internet]. London: UKaid; 2014. Available from: http://r4d.dfid.gov.uk/ Output/196116/Default.aspx.

64. World Health Organization. Task shifting: global recommendations and guidelines. Geneva, Switzerland; 2008.

65. Castner J, Foltz-Ramos K, Schwartz DG, Ceravolo DJ. A leadership challenge: staff nurse perceptions after an organizational team STEPPS initiative. J Nurs Adm. 2012:42:467-72.

66. Duygulu S, Kublay G. Transformational leadership training programme for charge nurses. J Adv Nurs. 2011;67:633-42.

67. Martin JS, Mccormack B, Fitzsimons D, Spirig R. Evaluation of a clinical leadership programme for nurse leaders: evaluation of a clinical leadership programme. J Nurs Manag. 2012;20:72-80.

68. McAlearney AS, Butler PW. Using leadership development programs to improve quality and efficiency in healthcare. J Healthc Manag. 2008:53:319-32

69. Cummings G, McLennan M. Advanced practice nursing: leadership to effect policy change. J Nurs Adm. 2005;35:61-6.

70. Fleiszer AR, Semenic SE, Ritchie JA, Richer M-C, Denis J-L. Nursing unit leaders' influence on the long-term sustainability of evidence-based practice improvements. J Nurs Manag. 2015;2015:12320.

71. Gifford WA, Davies B, Edwards N, Graham ID. Leadership strategies to influence the use of clinical practice guidelines. Nurs Leadersh. 2006;19:72-88

72. Edwards N, Davies B, Ploeg J, Virani T, Skelly J. Implementing nursing best practice guidelines: impact on patient referrals. BMC Nurs. 2007;6:4.

73. Edwards NC, Roelofs S. Strengthening nurses' capacity in HIV policy development in sub-Saharan Africa and the Caribbean: an international program of research and capacity building. Can J Nurs Res. 2007;39:187-9.

74. Edwards N, Webber J, Mill J, Kahwa E, Roelofs S. Building capacity for nurse-led research. Int Nurs Rev. 2009;56:88-94.

75. Davison CM, Kahwa E, Atkinson U, Hepburn-Brown C, Aiken J, Dawkins P, et al. Ethical challenges and opportunities for nurses in HIV and AIDS community-based participatory research in Jamaica. J Empir Res Hum Res Ethics. 2013;8:55-67.

76. Bender A, Edwards N, Kahwa E, Kaseje D. Developing capacity through a participatory action research approach. In: Edwards N, Kaseje D, Kahwa E, editors. Building and Evaluating Research Capacity in Healthcare Systems: Case Studies and Innovative Models. Cape Town, South Africa: University of Cape Town Press; 2016; pp. 53-100.

77. Mill J, Davison C, Richter S, Etowa J, Edwards N, Kahwa E, et al. Qualitative research in an international research program: maintaining momentum while building capacity in nurses. Int J Qual Methods. 2014;13:151-69.

78. Damschroder LJ, Aron DC, Keith RE, Kirsh SR, Alexander JA, Lowery JC. Fostering implementation of health services research findings into practice: a consolidated framework for advancing implementation science. Implement Sci. 2009:4:50

79. Mill JE, Ogilvie LD. Establishing methodological rigour in international qualitative nursing research: a case study from Ghana. J Adv Nurs. 2003:41:80-7.

80. UNAIDS. Report on the global AIDS epidemic [Internet]. Geneva, Switzerland: UNAIDS; 2010. Available from: http://www.unaids.org/ globalreport/Global_report.htm.

81. UNAIDS. The gap report. Geneva, Switzerland: UNAIDS; 2014. 
82. Sambo L, Chatora R, Goosen E. Tools for assessing the operationality of district health systems. Brazzaville: World Health Organization, Regional Office for Africa; 2003.

83. Edwards N, Davies B, Danseco E, Brosseau L, Pharand D, Ploeg J, et al. Evaluation of nursing best practice guidelines: clinical management, quality assurance and referrals. Ottawa: University of Ottawa School of Nursing; 2005. Oct. Report No.: CHRU \& NBPRU Publication No. M05-1.

84. Uys LR, Holzemer WL, Chirwa ML, Dlamini PS, Greeff M, Kohi TW, et al. The development and validation of the HIV/AIDS Stigma Instrument-Nurse (HASI-N). AIDS Care. 2009;21:150-9.

85. Corp IBM. IMB SPSS Statistics for Windows. Armonk: IBM Corp; 2013

86. R Core Team. R: a language and environment for statistical computing [Internet]. Vienna, Austria: R Foundation for Statistical Computing 2014. Available from: https://cran.r-project.org/doc/manuals/r-release/ fullrefman.pdf

87. Bureau of Labor Statistics. Job Openings and Labor Turnover Survey [Internet]. Bur. Labor Stat. [cited 2015 Aug 18]. Available from: http://www. bls.gov/jtt/.

88. Wu S, Li L, Wu Z, Liang L-J, Cao H, Yan Z, et al. A brief HIV stigma reduction intervention for service providers in China. AIDS Patient Care STDs. 2008;22:513-20.

89. Church K, Kiweewa F, Dasgupta A, Mwangome M, Mpandaguta E, Gomez-Olive FX, et al. A comparative analysis of national HIV policies in six African countries with generalized epidemics. Bull World Health Organ. 2015;93:437-512.

90. UNAIDS. Pan-Caribbean Partnership Against HIV/AIDS (PANCAP) launches its Justice for All Programme [Internet]. UNAIDS. 2013 [cited 2015 Oct 26]. Available from: http://www.unaids.org/en/resources/presscentre/ featurestories/2013/december/20131213pancapjustice.

91. Jagosh J, Bush PL, Salsberg J, Macaulay AC, Greenhalgh T, Wong G, et al. A realist evaluation of community-based participatory research: partnership synergy, trust building and related ripple effects. BMC Public Health. 2015:15:725.

92. Byskov J, Bloch P, Blystad A, Hurtig A-K, Fylkesnes K, Kamuzora P, et al. Accountable priority setting for trust in health systems-the need for research into a new approach for strengthening sustainable health action in developing countries. Health Res Policy Syst. 2009:7:23.

93. de Savigny D, Taghreed A. Systems thinking for health systems strengthening [Internet]. Geneva: World Health Organization; 2009. Available from: http://www.who.int/alliance-hpsr/resources/9789241563895/en/.

94. Kok MC, Kane SS, Tulloch O, Ormel H, Theobald S, Dieleman M, et al. How does context influence performance of community health workers in low- and middle-income countries? Evidence from the literature. Health Res Policy Syst. 2015;13:13.

95. CDI Study Group. Community-directed interventions for priority health problems in Africa: results of a multicountry study. Bull World Health Organ. 2010;88:509-18.

96. Chandrasekaran P, Dallabetta G, Loo V, Mills S, Saidel T, Adhikary R, et al. Evaluation design for large-scale HIV prevention programmes: the case of Avahan, the India AIDS initiative. AIDS Lond Engl. 2008;22 Suppl 5:S1-S15.

97. Smith T, Yu M, Kautsch M. A systematic review and meta-synthesis of effective nursing leadership. Pol Rev Health Sci. 2009;4:395-402.

98. Management Sciences for Health. Human resource management rapid assessment tool for public- and private-sector health organizations: a guide for strengthening HRM systems. Cambridge: Management Sciences for Health; 2005.

\section{Submit your next manuscript to BioMed Central and we will help you at every step:}

- We accept pre-submission inquiries

- Our selector tool helps you to find the most relevant journal

- We provide round the clock customer support

- Convenient online submission

- Thorough peer review

- Inclusion in PubMed and all major indexing services

- Maximum visibility for your research

Submit your manuscript at www.biomedcentral.com/submit
Biomed Central 